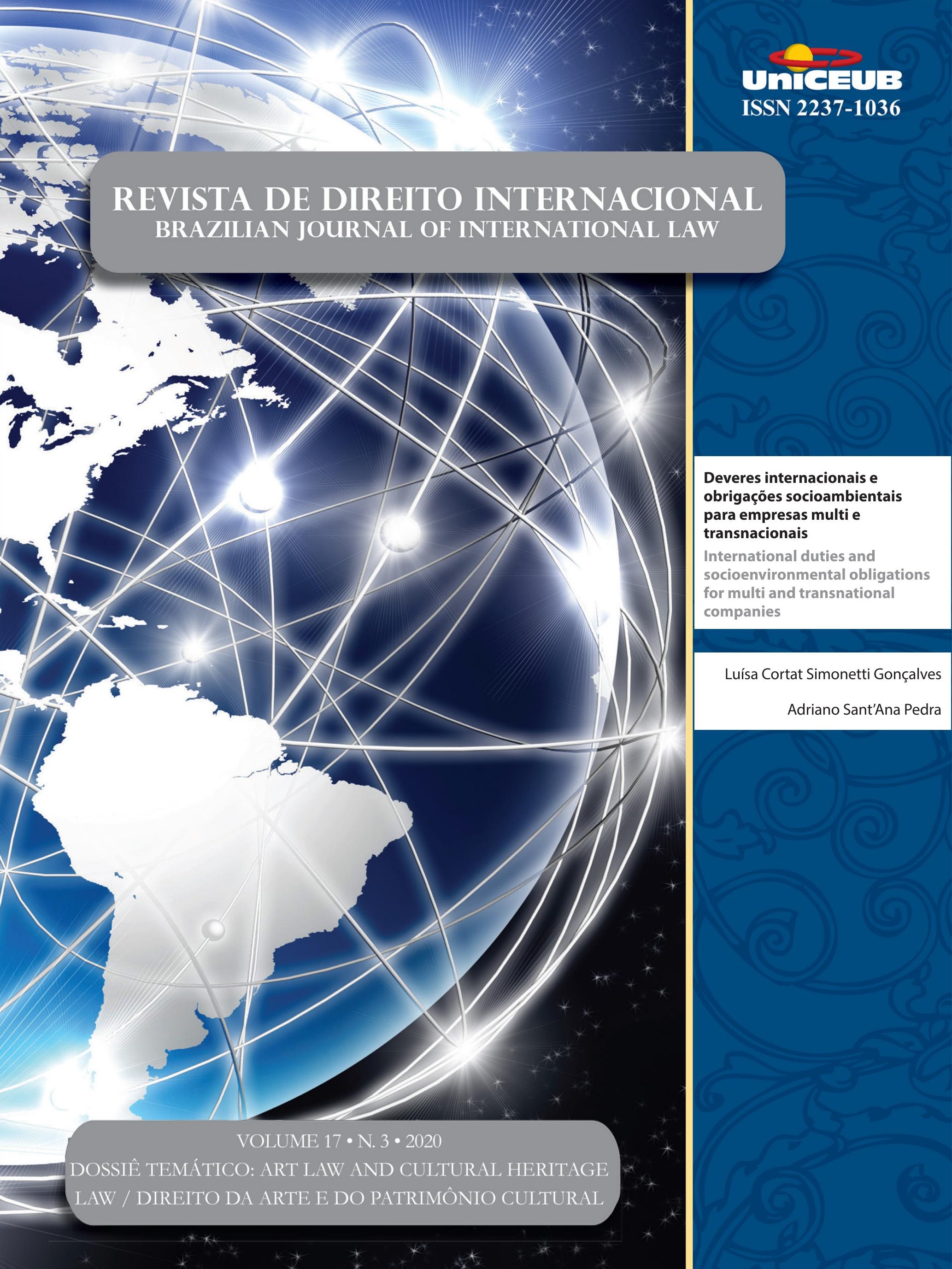




\section{Sumário}

EDITORIAL .20

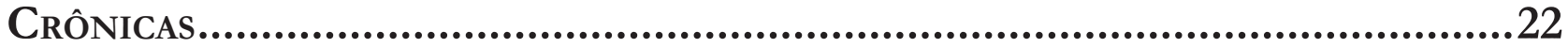

O COSTUME INTERNACIONAL COMO REFORÇO DA OBJEÇÃO BRASILEIRA À CLÁUSULA DO TRATAMENTO JUSTO E EQUITATIVO .24

Leonardo Vieira Arruda Achtschin

O PROCESSO LEGISLATIVO COMO GARANTIA PARA A OBTENÇÃo DO CONSENTIMENTO PRÉVIO DAS COMUnidades quilombolas de AlCÂNTARa

Gabriel de Oliveira Borba

Dossiê temático: Art Law and Cultural Heritage law / Direito da Arte e do Patrimônio cultural - Panorama Geral

Peoples' heritage or States' heritage? sovereignty in the UNESCO mechanism for THE SAFEGUARDING OF INTANGIBLE CULTURAL HERITAGE.

Aliki Gkana

The IMPACT OF THE UNESCO AND UNIDROIT CONVENTIONS AND THE EU DIRECTIVES ON THE INTERNATIONAL ART MARKET: AN ANALYSIS FIFTY YEARS AFTER THE INTRODUCTION OF THE OBLIGATION TO RETURN STOLEN OR ILLEGALLY EXPORTED CULTURAL GOODS 61

Geo Magri

Três pautas em destaque na agenda de diversidade Cultural da Unesco: Ambiente digiTAL, TRATAMENTO PREFERENCIAL E PARTICIPAÇÃO DA SOCIEDADE CIVIL............................76

Danilo Júnior de Oliveira, Maria Carolina Vasconcelos Oliveira e Ana Paula do Val

A 100 YEARS INSTITUTIONALIZED CULTURAL HERITAGE PROTECTION: FROM THE INSTITUTIONALIZED INTERNATIONAL COOPÉRATION INTELLECTUELLE TO THE HUMAN RIGHT TO CULTURAL HERITAGE

Lando Kirchmair 


\section{Aspectos Metodológicos do Direito da Arte e do Patrimônio}

Cultural

A proteção do PATrimônio CULTURAL EM NOVAS PERSPECTIVAS: ESTUdo COMPARAdo ENTRE A Kulturgutschutzgesetz e a Holocaust Expropriated Art Recovery Act of 2016.....111 Ardyllis Alves Soares

ArT-RELATED DispUTES AND ADR METHODS 127 Maria Beatrice Deli e Veronica Proietti

Due Diligence in Art Law and Cultural Heritage Law 150 Lisiane Feiten Wingert Ody

The Reception of Droit de Suite in International Law: Diagnosis and Remedy .... 170 Mickael R. Viglino

Direito da Arte e do Patrimônio Cultural: do Regional ao Local ....... 188

Câmara Cascudo e o legal Design - A Visualidade do Direito entre Provincianismo e GlobalizaÇão 190 Marcilio Toscano Franca Filho

A política da União Europeia no turismo: O turismo cultural e a sustentabilidade do PATRIMONNIO INDUSTRIAL PARA INTEGRAÇÃO DO BLOCO EUROPEU

Maraluce Maria Custódio e Fernando Barotti dos Santos

Diálogo entre la Corte Interamericana de Derechos Humanos y el Tribunal Europeo de Derechos Humanos en torno al Derecho humano a la identidad cultural..223 Juan Jorge Faundes

Digital ART AND THE BELT AND ROAD INITIATIVE: CHALLENGES AND OPPORTUNITIES 257 Dan Wei e Ângelo Rafael

Policing heritage crime in Latin America. .275 Naomi Oosterman e Donna Yates 
The principles of Cultural Heritage Law based on the Polish Law as an example.292 Małgorzata Joanna Węgrzak e Kamil Zeidler

Heritage Protection in INTERNATIONAL LAw AND NATIONAL LAW: INSIGHTS INTO THE CASE OF VIETNAM

Yen Thi Hong Nguyen e Dung Phuong Nguyen

THE APPROPRIATION OF THE CARIOCA INTANGIBLE CULTURAL HERITAGE BY AN ENTREPRENEURIAL LOGIC

Mário Ferreira de Pragmácio Telles

A Propósito del CARÁcter UNIVERSAL DEL aCCESO A LA CULTURA EN INTERNET: UN ANÁlisis DESDE EL PRISMA INTERNACIONAL Y LA EXPERIENCIA DEL ORDENAMIENTO JURÍDICO CUBANO 344 Janny Carrasco Medina

Direito Humanitário e Arte

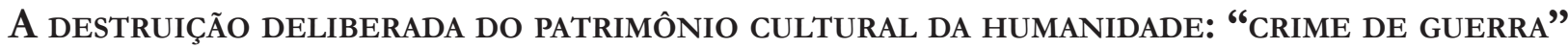
OU "CRIME CONTRA A HUMANIDADE"? Juliette Robichez

Protection OF CULTURAL PROPERTY UNDER INTERNATIONAL HUMANITARIAN LAW: EMERGING TRENDS

Niteesh Kumar Upadhyay e Mahak Rathee

Direito do Mar/Marítimo e Arte.

The underwater Cultural heritage Regime: SOME PROBlems AND POSSible SOlutions. 412 Elina Moustaira

El ROL DEL DERECHO EN LA CONSTRUCCIÓN DEL PATRIMONIO CULTURAL SUBACUÁTICO: APRECiaciones a partirdel estudio del CASo de la Corbeta Inglesa SwifT en Argentina .. 424 Norma Elizabeth Levrand e Nadia Bressan Bernhardt 
INDIGENOUS REFUGEES AND CULTURAL EROSION: POSSIBILITIES AND LIMITS OF INTERNATIONAL REFUGEE AND INDIGENOUS PEOPLES LAW IN THE PROTECTION OF INDIGENOUS CULTURAL EXPRESSIONS RELATED TO TRADITIONAL LAND AND NATIVE LANGUAGE. .440 Rickson Rios Figueira

O RETRATO DE EDMOND BELAMY E A INTERFACE ENTRE ARTE E INTELIGENCIA ARTIFICIAL: POR UMA NOVA DEFINIÇÃo DE AUTORIA E DIREITOS DE PROPRIEDADE INTELECTUAL

Marla Meneses do Amaral Leite Mangiolardo, Patrícia Silva de Almeida e Jonathan Barros Vita

Argumentative aspects of Declaration on the Importance and Value of Universal Museums (2002) 479

Agnieszka Plata

A DestinaÇão dos bens CUlturais EM PROCESSOS PENAIS: A ARTE COMO REPARAÇÃo COLETIVA 488

Inês Virgínia Prado Soares e Otavio Venturini

A Justiça de Pieter Bruegel: direito, violência e a venda nos (nossos) olhos. .501 Rafael Lazzarotto Simioni e Cícero Krupp

Artigos Sobre outros temas

DEVERES INTERNACIONAIS E OBRIGAÇÕES SOCIOAMBIENTAIS PARA EMPRESAS MULTI E TRANSNACIONAIS

Luísa Cortat Simonetti Gonçalves e Adriano Sant'Ana Pedra

Maternidade por substituição: perspectivas da ConferênCia da Haia e suas potenciais INFLUÊNCIAS NO REGRAMENTO BRASILEIRO

Tatiana de A. F. R. Cardoso Squeff e Fernanda Rezende Martins

EL (LARGO) CAMINO DE RECONOCIMIENTO Y EJECUCIÓN DE LAUDOS ARBITRALES DE INVERSIÓN

Thiago Paluma, Ivette Esis e Gabriel Briceño 
A INTERPRETAÇÃo EVOLUTIVA DA CONVENÇÃo AMERICANA SOBRE DiREITOS HUMANOS: UMA REVISÃO DOCUMENTAL DO PERÍODO 1988-2018

Breno Baía Magalhães

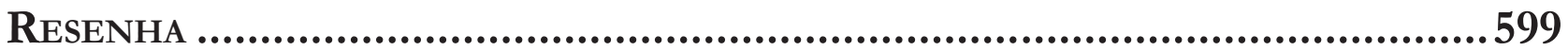

Autonomous Weapons Systems and InTERnATIONAL LAw: A STUDY ON HUMAN-MACHINE INTERACTIONS IN ETHICALLY AND LEGALLY SENSITIVE DOMAINS

Aziz Tuffi Saliba e Lutiana Valadares Fernandes Barbosa 


\title{
Deveres internacionais e obrigações socioambientais para empresas multi e transnacionais*
}

\author{
International duties and socioenvironmental \\ obligations for multi and transnational \\ companies
}

Luísa Cortat Simonetti Gonçalves**

Adriano Sant'Ana Pedra***

* Recebido em 17/07/2020

Aprovado em 06/04/2021

** Doutora em Direito pela Universidade de Maastricht (Holanda),com bolsa da CAPES, e Doutoranda em Direitos e Garantias Fundamentais pela Faculdade de Direito de Vitória - FDV (CAPES 5). Mestre em Direitos e Garantias Fundamentais pela FDV, bolsista do Fundo de Amparo à Pesquisa do Espírito Santo (FAPES). Especialista em Economia e Meio Ambiente pela Universidade Federal do Paraná - UFPR. Graduada em Direito pela FDV. Membro do METRO - Institute for Transnational Legal Research (Holanda) e membro do Grupo de Pesquisa Estado, Democracia Constitucional e Direitos Fundamentais da FDV. Coordenadora e professora universitária da FDV.

E-mail: luisacsg@gmail.com

*** Doutor em Direito do Estado pela PUC/ SP. Mestre em Direitos e Garantias Fundamentais pela FDV e em Física Quântica pela UFES. Bacharel em Direito e em Física pela UFES. Realizou pós-doutorado na Universidade de Coimbra. Professor permanente do Programa de Pós-Graduação Stricto Sensu - Mestrado e Doutorado - em Direitos e Garantias Fundamentais da FDV. Professor colaborador do Programa de Pós-Graduação em Gestão Pública Mestrado Profissional - da UFES. Professor do Curso de Direito da FDV. Procurador Federal. E-mail: adrianopedra@fdv.br

\section{Resumo}

A lacuna de governança relativamente a empresas multi e transnacionais no contexto internacional é um ponto constante de preocupações quando o assunto é proteção aos direitos humanos e ao meio ambiente. Isso ocorre, principalmente, devido à dificuldade de impor obrigações por meio do direito internacional, no qual a autoridade é compartilhada entre as nações - portanto, onde nenhuma delas exerce soberania - e no qual as empresas não são sujeitos de direito. Tal dificuldade vem sendo superada por meio de diferentes estratégias, embora ainda escassas e sem enquadramento específico na Teoria do Direito internacional. No presente artigo, analisam-se três dessas estratégias, relacionando-as à possibilidade de imposição de deveres humanos internacionais às empresas, posto que pode significar caminho para o robustecimento das obrigações socioambientais corporativas. Questiona-se, portanto: é possível estabelecer obrigações de proteção socioambiental para empresas multi e transnacionais a partir do Direito Internacional Público e da teoria dos deveres fundamentais? Para se responder à pergunta de pesquisa, aplica-se o método dialético, passando pela análise de três casos específicos: (i) potencial aplicabilidade da teoria da horizontalidade aos deveres humanos; (ii) possíveis consequências hard para soft law; (iii) a Convenção da Basileia como exemplo de previsão de obrigações a empresas em um instrumento hard law. As análises permitem concluir pela possibilidade de se falar em horizontalidade na aplicação dos deveres humanos; pela possibilidade de vincular as empresas, internacionalmente, relativamente aos compromissos ambientais por ela assumidos, ainda que soft, e pela possibilidade de impactar empresas privadas através de normas internacionais originariamente dirigidas aos Estados. Portanto, o artigo inova ao demonstrar avanços, efetivos e potenciais, rumo à imposição de deveres humanos a empresas privadas no âmbito jurídico internacional.

Palavras-chave: deveres humanos; responsabilidade corporativa; direito internacional; proteção socioambiental. 
Abstract

The governance gap related to multi and transnational companies in the international context is an aspect of constant concerns when the subject is the protection to human rights and to the environment. This happens mainly because of the difficulty on imposing obligations through the international law, in which the authority is shared between nations - thus, in which none of them has sovereignty - and in which the companies are not subjects of law. Such a difficulty is being overcome with different strategies, although still scarce and without specific framing in the in the international law theory. This paper analyzes three of those strategies, relating them to the possibility of imposing international human duties to companies, once it may mean a path to the strengthening of the corporate socio-environmental obligations. It asks, then: is it possible to establish obligations of socio-environmental protection to multi and transnational companies from the Public International Law and the theory of fundamental duties? To answer the research question, the dialetic method is used, going through the analysis of three specific cases: (i) potential applicability of the horizontality theory to human duties; (ii) possible hard consequences of soft law; (iii) the Basel Convention as an example of obligation provisions to companies in a hard law instrument. The analysis enable to conclude for the possibility of horizontality in the application of human duties; for the possibility of internationally binding companies regarding the environmental commitments undertaken by them, even if soft ones; As análises permitem concluir pela possibilidade de se falar em horizontalidade na aplicação dos deveres humanos; pela possibilidade de vincular as empresas, internacionalmente, relativamente aos compromissos ambientais por ela assumidos, ainda que soft; e pela possibilidade de impactar empresas privadas através de normas internacionais originariamente dirigidas aos Estados. Portanto, o artigo inova ao demonstrar avanços, efetivos e potenciais, rumo à imposição de deveres humanos a empresas privadas no âmbito jurídico internacional.

Keywords: human duties; corporate responsibility; international law; socio-environmental protection.

\section{Introdução}

O processo de internacionalização dos Direitos Humanos possui origens na redefinição dos paradigmas clássicos do Direito Internacional, embasados no protagonismo exclusivo dos Estados. Principalmente, a partir das discussões no período pós-guerras, preocupadas em operacionalizar a proteção da pessoa humana, passa-se a reconhecer o indivíduo como um sujeito de direito internacional e surgem discussões sobre a possibilidade de reconhecimento da personalidade jurídica internacional de empresas transnacionais.

Principalmente após a II Guerra Mundial, muito se evoluiu em termos de proteção dos direitos humanos no âmbito internacional. Já as discussões sobre proteção ambiental, são mais recentes. Estas são inseridas na agenda internacional principalmente a partir de 1972, com a Conferência de Estocolmo, ensejada pelas constatações do Relatório Os Limites do Crescimento ${ }^{1}$, do Clube de Roma. Desde então, muito também se evoluiu, ainda que sem o escopo de proteção de que se cercou os direitos humanos, por exemplo.

Apesar de todo o avanço, sabe-se que ainda há diversos desafios a serem superados. Muitos deles decorrentes da própria atuação estatal, porém muitos também em virtude da ação de atores privados, dentre os quais indivíduos e empresas. Nesse sentido a discussão sobre deveres fundamentais ganha destaque, embora, ainda assim, pouco se reflita acerca de seus contornos, consequências, e sobre sua teoria em geral.

Pesquisa anterior recente ${ }^{2}$ já delimitou os contornos de uma Teoria de Direito Internacional dos deveres humanos, em especial no que se refere aos atores privados. Relativamente às empresas multinacionais, impõem-se desafios adicionais, como estabelecer deveres para atores que não são sujeitos de direito internacional. Entretanto, as respostas necessárias aos impactos causados por tais atores urgem ações mais rápidas do que a evolução natural dos mecanismos do direito internacional.

A literatura acadêmica de diferentes áreas já demonstra algumas ferramentas com potencial de gerar obrigações para empresas no âmbito internacional, mas

MEADOWS Dennis et. al. Os Limites do Crescimento. Massachussets: Donella Meadows, 1972.

2 GONÇALVES, Luísa Cortat Simonetti; PEDRA, Adriano Sant'Ana. Direito Internacional dos Deveres Humanos: reflexões para uma teoria internacional envolvendo atores privados. 2019. (prelo) 
esses conhecimentos ainda não foram consolidados e analisados sob a perspectiva dos deveres fundamentais. Por isso, o presente estudo enfrenta a seguinte questão: é possível estabelecer obrigações de proteção socioambiental para empresas multi e transnacionais a partir do Direito Internacional Público e da Teoria dos Deveres Fundamentais?

A fim de se chegar a uma resposta para questão tão complexa neste momento tão inicial das teorias, mostra-se necessário um corte mais próximo de casos específicos. Por isso, a partir de conceitos como deveres fundamentais, deveres humanos e responsabilidade corporativa - deslindados ao longo do texto -, enfrentaremos três questões secundárias: (i) pode-se falar em horizontalidade de aplicação dos deveres humanos? (ii) seria possível derivar análogos internacionais de aplicações que têm sido utilizadas no âmbito nacional para vincular empresas a seus compromissos ambientais, como por meio do direito consumerista e do direito contratual? (iii) é possível impactar regras impostas às empresas privadas por meio de normas dirigidas aos Estados, como normas de comércio internacional?

A metodologia empregada é a dialética, que se caracteriza justamente por analisar as questões em foco no contexto em que se manifestam, observando suas complexidades, dualidades e até aparentes contradições, em busca da síntese que permita apresentar soluções, ainda que provisórias, aos problemas apresentados. A adequação desse método se mostra mais evidente posto que a situação a ser enfrentada se desenha enquanto um movimento, o qual é formado por continuidades e descontinuidades e perante o aparecimento de choques e contradições. Além disso, a temática parece perpassar, necessariamente, a construção por meio de saltos qualitativos e superação.

O artigo estrutura-se, então, em quatro tópicos. No tópico 1 , serão introduzidas as teorias internacionais e de deveres fundamentais relevantes para o estudo. Nos tópicos 2 a 4, serão analisadas, respectivamente, as três perguntas secundárias. A conclusão segue, indicando que todos esses caminhos apresentam potencial para a imposição de deveres humanos a empresas privadas no âmbito jurídico internacional.

\section{Direito internacional ambiental e deveres humanos}

A investigação tem pontos de partida de duas construções teóricas distintas: o Direito Internacional dos Deveres Humanos e Responsabilidade Corporativa ${ }^{3}$.

Em verdade, o campo do Direito Internacional dos Deveres Humanos ainda não é um campo reconhecido do Direito. Trata-se de proposta elaborada em artigo anterior ${ }^{4}$. Tal artigo remonta às origens do Direito Internacional dos Direitos Humanos para compreender o atual estado da arte nesse campo. ${ }^{5}$ A partir daí, analisa-se a escalada de complexidade ${ }^{6}$ das relações, política e direito internacionais, para uma melhor compreensão dos desafios reais que se colocam.

Diversos são os pontos em comum entre os direitos e os deveres fundamentais nesse contexto global, como o gap de governança ${ }^{7}$, e compreender a evolução do Direito Internacional dos Direitos Humanos permitiu verificarem-se as condições para a proposição do referido Direito Internacional dos Deveres Humanos. Em termos conceituais, então, passou-se à adaptação do conceito de deveres fundamentais construído no contexto brasileiro, para o contexto internacional.

O conceito original é: "dever fundamental é uma categoria jurídico-constitucional, fundada na solidarie-

3 A expressão Responsabilidade Corporativa é utilizada neste projeto em sentido amplo, considerando-se como sinônimo de expressões como Responsabilidade Social Corporativa e Responsabilidade Socioambiental Corporativa.

4 GONÇALVES, Luísa Cortat Simonetti; PEDRA, Adriano Sant'Ana. Direito Internacional dos Deveres Humanos: reflexões para uma teoria internacional envolvendo atores privados. 2019. (prelo)

5 A partir de autores como

DUDEK, Wanilton. Teoria do Estado Moderno: Leituras Econômicas e Culturalistas. Ensino e Pesquisa. Paraná, Maio 2008, v.1, n.5, pp. 6-16.

BOBBIT, Philip. A guerra e a paz na história moderna: o impacto dos grandes conflitos e da política na formação das nações. Rio de Janeiro: Campus, 2003.

CASTELO BRANCO, Patrícia Martins; DA SILVA, Fábio Luiz. História Moderna II. 1. ed. São Paulo: Pearson Prentice Hall, 2009.

TOFFLER, Alvin. A terceira onda (7. ed. ed.). Rio de Janeiro: Editora Record, 1980.

6 Disponível em, e.g.: EBBESON, Jonas. The rule of law in governance of complex socio-ecological changes. Global Environmental Change 20(2010). pp. 414-422. p. 420.

7 SCHERER, Andreas Georg; PALAZZO, Guido. Globalization and Corporate Social Responsibility. In: CRANE, A.; MCWILLIAMS, A.; MATTEN, D.; MOON, J.; SIEGEL, D.J. (eds). The Oxford Handbook of Corporate Social Responsibility, Oxford: Oxford University Press, 2008. pp. 413-431. 
dade, que impõe condutas proporcionais àqueles submetidos a uma determinada ordem democrática, passíveis ou não de sanção, com a finalidade de promoção de direitos fundamentais". 89 A proposta conceitual de

8 GONÇALVES, Luísa Cortat Simonetti; FABRIZ, Daury César. Dever Fundamental: a construção de um conceito. In: DE MARCO, Christian Magnus; et al. Série Direitos Fundamentais Civis: teoria geral e mecanismos de efetividade no Brasil e na Espanha - tomo I. Joaçaba: editora Unoesc, 2013. p. 92.

9 A construção coletiva desse conceito se deu a partir de uma revisão de literatura. Para algumas das discussões consideradas, disponível em, e.g.:

ALEGRE MARTÍNEZ, M. Á. Los deberes en la constitución española: esencialidad y problemática. Teoría y Realidad Constitucional, n. 23, 2009.

BAYÓN MOHINO, J. C. Los deberes positivos generales y la determinación de sus límites (observaciones al artículo de Ernesto Garzón Valdés). Doxa, n. 3, 1986.

DÍAZ REVORIO, F. J. Derechos humanos y deberes fundamentales. Sobre el concepto de deber constitucional y los deberes en la Constitución Española de 1978. Revista del Instituto de Ciencias Jurídicas de Puebla, v. 5, n. 28, 2011.

DI COSIMO, G. Dovere di difesa della patria, servizio militare, servizio civile. Archivio Pace Diritti Umani, Padova, p. 55-66, 09 nov. 2011.

GARZÓN VALDÉS, E. Algunos comentarios críticos a las críticas de Juan Carlos Bayón y Francisco Laporta. Doxa, v. 3, 1986 .

GARZÓN VALDÉS, E. Los deberes positivos generales y su fundamentación. Doxa, v. 3, 1986b.

KOUBI, M. G. La déférence, un devoir sans droit? Communications, v. 69, p. 201-214, 2000.

LAKATOS, Eva Maria; MARCONI, Marina de Andrade. Metodologia Cientifica. 5. ed. rev. ampl. São Paulo: Atlas, 2010.

LANCHESTER, F. Los deberes constitucionales en el derecho comparado. Revista de Derecho Constitucional Europeo, v. 7, n. 13, 2010. LAPORTA, F. J. Algunos problemas de los deberes positivos generales (observaciones a un artículo de Ernesto Garzón Valdés). Doxa, n. 3, 1986 .

MEYER-BISCH, P. Les devoirs de l'homme: de la réciprocité dans les droits de l'homme. Fribourg: Étidions Universitaires, 1989.

NABAIS, J. C. A face oculta dos direitos fundamentais: os deveres e os custos dos

direitos. Revista Direito Mackenzie, São Paulo, ano 3, n. 2, p. 11-30, 2002.

NABAIS, J. C. Por uma liberdade com responsabilidade. Coimbra: Coimbra, 2007.

PALOMBELLA, G. De los derechos y de su relación con los deberes y los fines. Derechos y Libertades, n. 17, 2007.

PECES-BARBA MARTÍNEZ, G. Los deberes fundamentales. Doxa, n. 4, 1987.

PEDRA, Adriano Sant'Ana. A Importância dos Deveres Humanos na Efetivação de Direitos. In: ALEXY, Robert; et. al. (org.) Niveis de Efetivação dos Direitos Fundamentais Civis e Sociais: um diálogo Brasil e Alemanha. Joaçaba: Editora Unoesc, 2013. pp. 281-301.

ROCA, V. ¿De qué hablamos cuando hablamos de deberes jurídicos? (Algunas consideraciones sobre las fuentes del Derecho a partir de la tesis de Nino del caso especial). Doxa, n. 25, 2002.

RUBIO LLORENTE, F. Los deberes constitucionales. Revista Española de Derecho Constitucional, Madrid, v. 21, n. 61, 2001.

VARELA DÍAZ, S. La idea de deber constitucional. Revista Española base para a construção de uma teoria de Direito Internacional dos Deveres Humanos é que um dever humano internacional é "a categoria normativa internacional fundada na solidariedade, que impõe condutas proporcionais àqueles submetidos à ordem democrática internacional, passíveis ou não de sanção, com a finalidade de promoção de direitos fundamentais". ${ }^{10}$

As construções então não somente confirmaram a possibilidade de uma teoria de Direito Internacional dos Deveres Humanos como também permitiram certo otimismo na utilização dos organismos e estruturas já existentes para o Direito Internacional dos Direitos Humanos. Por outro lado, apesar de a proposta cumprir os requisitos de considerar os novos atores de direito internacional e de pautar-se nos princípios e valores de direito internacional, uma das principais dificuldades que ela levanta é "a identificação e o âmbito de extensão do reconhecimento dos sujeitos privados de deveres internacionais, em especial no que tange às corporações". ${ }^{11}$ Justamente daí advém o presente estudo.

Diante da dificuldade de lidar com as empresas privadas no âmbito internacional, uma das preocupações centrais da literatura acadêmica e das organizações civis são os desafios em lidar com as externalidades negativas que elas causam. Nesse sentido, são particularmente relevantes os impactos aos direitos humanos e ao meio ambiente, sendo este central nas análises deste artigo.

Portanto, importa a análise pretendida no presente artigo, no sentido de se identificar a viabilidade ou não de imposição de obrigações acessórias a estes que não são sujeitos de direito internacional, com base em teoria de um Direito Internacional dos Deveres Humanos. Os tópicos a seguir enfrentam justamente três potenciais situações internacionais em que emergem obrigações para empresas. No tópico a seguir, a discussão é se se pode falar em horizontalidade de aplicação dos deveres humanos. No que se segue, a análise é de viabilidade de derivar análogos internacionais de aplicações que têm sido utilizadas no âmbito nacional para dar força co-

\section{de Derecho Constitucional, n. 4, 1982.}

VERNENGO, R. J. Deberes prescriptivos y deberes descriptivos. Anuario de Filosofia del Derecho. Madrid, p. 263-273, 1993.

10 GONÇALVES, Luísa Cortat Simonetti; PEDRA, Adriano Sant'Ana. Direito Internacional dos Deveres Humanos: reflexões para uma teoria internacional envolvendo atores privados. 2019. (prelo) p. 19. 11 GONÇALVES, Luísa Cortat Simonetti; PEDRA, Adriano Sant'Ana. Direito Internacional dos Deveres Humanos: reflexões para uma teoria internacional envolvendo atores privados. 2019. (prelo) p. 27. 
gente a compromissos não vinculantes assumidos pelas empresas, como por meio do direito consumerista e do direito contratual. No tópico seguinte, analisa-se a possibilidade de surgimento de regras às empresas privadas por meio de normas dirigidas aos Estados, como normas de comércio internacional. Para tanto, utiliza-se o exemplo da Convenção da Basileia.

\section{Horizontalidade dos deveres humanos internacionais}

Discutir uma possível horizontalidade desses deveres humanos internacionais significa aplicar uma teoria nacional de direitos humanos ao conceito internacional de deveres. Assim, cumpre inicialmente destacar alguns aspectos da evolução internacional da proteção dos direitos humanos e da proteção ambiental, bem como algumas de suas interrelações, antes de ser possível analisar possíveis paralelos. Para isso, baseia-se em reflexões de Gonçalves. ${ }^{12}$

Conforme mencionado, soluções puramente estatais parecem ser ineficientes principalmente em dois níveis. O primeiro refere-se à falha no reconhecimento dos novos atores no cenário político, especialmente indivíduos e corporações. O segundo à inadequação do desenho e do alcance das instituições para lidar com uma nova, e mais complexa, ordem. Algumas dessas falhas ficaram particularmente evidentes durante a Segunda Guerra Mundial, levando a mudanças no Direito Internacional que visavam a uma maior proteção dos direitos humanos. ${ }^{13}$ Após o Pacto Internacional sobre Direitos Civis e Políticos e o Pacto Internacional sobre Direitos Econômicos, Sociais e Culturais serem efetivados em 1976, os três documentos passaram a formar a chamada Declaração Internacional dos Direitos Humanos (DUDH). A DUDH é considerada a linha jurídica basilar para o direito internacional dos direitos humanos moderno, ${ }^{14} \mathrm{e}$

\footnotetext{
12 GONÇALVES, Luísa Cortat Simonetti. Legal Remedies against the Plastic Pollution of the Oceans: an analysis of the attempts from public international law and private initiatives to face the plastic soup. Bilt: Proefschriftmaken, 2020. p. 74-82.

13 ALSTON, Philip; GOODMAN, Ryan. International Human Rights. Oxford: Oxford University Press, 2013. p.139.

14 BADERIN, Mashood A.; SSENYONJO, Manisuli. Development of International Human Rights Law Before and After the UDH. In: BADERIN, Mashood A.; SSENYONJO, Manisuli (eds.). International Human Rights Law: Six Decades after the UDHR and Beyond. Farnham: Ashgate, 2010. pp. 3-27. p. 3.
}

sua declaração lançou a proteção universal dos direitos humanos sob o Estado de Direito. ${ }^{15}$

Embora a DUDH tenha sido o primeiro instrumento da ONU listando direitos humanos internacionalmente reconhecidos ${ }^{16}$ não é surpresa que o direito ao meio ambiente equilibrado não esteja entre eles, já que as discussões internacionais relacionadas à proteção ambiental apenas ganharam corpo da década de 1970 em diante.

Abordagens iniciais para uma regulação internacional de questões ambientais emergiram muito antes, desde fins do séc. XIX, "nomeadamente as regras regendo a exploração de certos recursos, dano transfronteiriço e o uso de recursos hídricos compartilhados". ${ }^{17}$ No entanto, a atenção internacional para problemas ambientais apenas foi catalisada durante a década de $1960,{ }^{18}$ culminando no importante marco que é o relatório Os Limites do Crescimento, ${ }^{19}$ elaborado pelo Clube de Roma em 1972. Nele, um grupo de especialistas do Instituto de Tecnologia de Massachusetts (MIT) explorou diferentes cenários, demonstrando as contradições inerentes ao comportamento exploratório, e destacou possibilidades para a sociedade reconciliar progresso (sustentável) com limites ambientais.

\section{A partir dessas reflexões,}

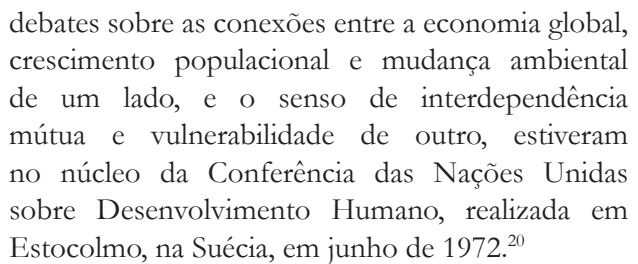

15 GLENDON, M.A. The Rule of Law in the Universal Declaration of the Human Rights. Northwestern Journal of International Human Rights, 2(1), 2004, article 5 [online]. Available on: https:// scholarlycommons.law.northwestern.edu/cgi/viewcontent. cgi? article $=1008 \&$ co ntext $=$ njihr. Accessed on February 26, 2020. p. 2.

16 BADERIN, Mashood A.; SSENYONJO, Manisuli. Development of International Human Rights Law Before and After the UDH. In: BADERIN, Mashood A.; SSENYONJO, Manisuli (eds.). International Human Rights Law: Six Decades after the UDHR and Beyond. Farnham: Ashgate, 2010. pp. 3-27. p. 8.

17 DUPUY, Pierre-Marie; VIÑUALES, Jorge E. International Environmental Law. Cambridge: Cambridge University Press, 2015. p. 4.

18 DUPUY, Pierre-Marie; VIÑUALES, Jorge E. International Environmental Law. Cambridge: Cambridge University Press, 2015. p. 8.

19 MEADOWS Dennis et. al. Os Limites do Crescimento. Massachussets: Donella Meadows, 1972.

20 Tradução livre. No original: "Debates over the links between the global economy, population growth, and environmental change on the one hand, and the sense of mutual interdependence and vulner- 
Ainda assim, apenas em 1987, a expressão desenvolvimento sustentável foi forjada, no documento Nosso Futuro Comum, também conhecido como Relatório Brundtland, baseado na Conferência da ONU sobre Meio Ambiente e Desenvolvimento (Eco-92). Essa conferência foi um passo essencial para abraçar um desenvolvimento que "atenda às necessidades das presentes gerações sem comprometer a capacidade das futuras gerações de atender às suas próprias necessidades", ${ }^{21}$ principalmente por meio da adoção da Agenda $21^{22} \mathrm{e}$ da Declaração do Rio sobre Meio Ambiente e Desenvolvimento. ${ }^{23}$

"Desde Estocolmo, as instituições globais vêm se tornando cada vez mais ativas na promoção global da proteção ambiental". ${ }^{24}$ Dentre elas há, por exemplo, o Programa das Nações Unidas para o Meio Ambiente (PNUMA), a Comissão para o Desenvolvimento Sustentável (CDS) e várias outras, todas dentro ou conectadas às Nações Unidas. Com isso, voltamos à importância da ONU e da estrutura do DIDH.

"O processo de universalização dos direitos humanos permitiu a formação de um sistema internacional de proteção desses direitos - forma-se, assim, o sistema normativo global de proteção dos direitos humanos, no âmbito das Nações Unidas". ${ }^{25}$ Tal sistema, atualmente, inclui não apenas organismos das Nações Unidas em si, mas também sistemas regionais - Interamericano, Europeu e Africano - e diversas normas de diferentes

ability on the other, were at the core of the United Nations Conference on the Human Environment, held in Stockholm, Sweden, in June 1972".

CLAPP, Jennifer; DAUVERGNE, Peter. Brief History of International Environmental Cooperation. In: NICHOLSON, Simon; WAPNER, Paul (eds.). Global Environmental Politics: from person to planet. New York: Routledge, 2016, pp. 121-136. p. 124.

21 UNITED NATIONS - UN. Report of the World Commission on Environment and Development, Our Common Future (UN Doc. A/42/427, 4 August 1987), Annex. Available at: https://sustainabledevelopment.un.org/content/documents/5987ourcommonfuture.pdf. Accessed on September 23, 2018.

22 UNITED NATIONS. Agenda 21. 1992.

23 UNITED NATIONS. The Rio Declaration on Environment and Development. 1992.

${ }^{24}$ CLAPP, Jennifer; DAUVERGNE, Peter. Brief History of International Environmental Cooperation. In: NICHOLSON, Simon; WAPNER, Paul (eds.). Global Environmental Politics: from person to planet. New York: Routledge, 2016, pp. 121-136. p. 134.

25 PIOVESAN, Flávia. Sistema Internacional de Proteção dos Direitos Humanos. I Colóquio Internacional de Direitos Humanos. São Paulo, Brasil, 2001. Available at: http://www.dhnet.org.br/direitos/sip/textos/a_pdf/piovesan_sip.pdf. Accessed on: Octorber 26, 2016. naturezas e tanto no nível internacional quanto no regional. Independentemente das interconexões entre direitos humanos e proteção ambiental, o direito ao meio ambiente equilibrado $^{26}$ ainda não é considerado um direito humano no direito internacional.

Apesar da evolução paralela ao longo de 60 anos, desde as declarações feitas em Estocolmo, em 1972, há uma busca por base jurisprudencial para conectar o DIDH e o Direito Internacional Ambiental (DIA). ${ }^{27} \mathrm{~A}$ própria ONU reconhece tal interconexão:

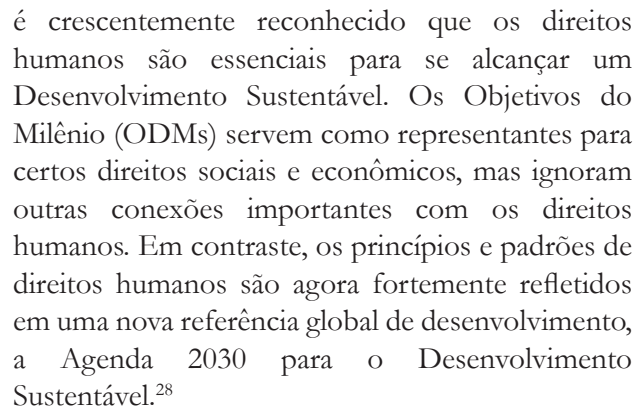

Em 1994, Fatma-Zohra Ksentini, relatora especial da ONU sobre resíduos tóxicos, apresentou seu relatório $^{29}$ sobre direitos humanos e meio ambiente, expondo a importância de se reconhecer o direito ao meio ambiente saudável como um direito humano. O Relatório Ksentini, como ficou conhecido, propôs um rascunho de princípios em direitos humanos e meio ambiente. Mais tarde, a discussão foi intensificada nos organismos da ONU, a ponto de ser indicado um relator especial - John Knox - pelo Conselho de Direitos Humanos da ONU em 2015, após ter sido Especialista Indepen-

26 Também chamado de: direito ao meio ambiente saudável, direito ao meio ambiente, e similares.

27 ANTON, Donald K.; SHELTON, Dinah L. Environmental Protection and Human Rights. New York: Cambridge University Press, 2011. p. 118-119.

28 Tradução livre. No original: "It is increasingly recognized that human rights are essential to achieve Sustainable Development. The Millennium Development Goals (MDGs) served as a proxy for certain economic and social rights but ignored other important human rights linkages. By contrast, human rights principles and standards are now strongly reflected in an ambitious new global development framework, the 2030 Agenda for Sustainable Development".

United Nations - UN. Human Rights and the 2030 Agenda for Sustainable Development. 2016. Available at: <http://www.ohchr.org/ EN/Issues/MDG/Pages/The2030Agenda. aspx>. Accessed on 1 August 2016.

29 United Nations: Economic and Social Council. Review of Further Developments in Fields with which the Sub-Comission Has Been Concerned - Human Rights and the Environment. Final report prepared by Mrs. Fatma Zohra Ksentini, Special Rapporteur. 6 July 1994. Available at: https://digitallibrary.un.org/record/226681. Accessed on February $28,2020$. 
dente desde 2012. Isso resultou na proposição de princípios para direitos humanos e meio ambiente ${ }^{30}$ e em conclusões tais como: há vários esforços, nacionais e internacionais, reconhecendo, ou encaminhando para o reconhecimento, do direito humano ao meio ambiente equilibrado; uma conexão inerente entre direitos humanos tais como vida e saúde e o direito ao meio ambiente equilibrado; e um movimento rumo ao reconhecimento internacional, como com o Pacto Global para o Meio Ambiente. $^{31}$

Tais interconexões já permitem a utilização de parte da estrutura construída para o DIDH, por meio dos organismos da ONU ou até mesmo por meio de decisões judiciais. No que diz respeito a cortes, entretanto, há várias especificidades, principalmente decorrentes do fato de que o direito humano ao meio ambiente equilibrado não é ainda internacionalmente reconhecido. Consequentemente, as cortes internacionais, de modo geral, não têm competência - a qual precisa ser explícita - para analisar violações ambientais. Isso levanta várias e interessantes discussões, tais como as em andamento nas cortes regionais de proteção dos direitos humanos $^{32}$. O debate sobre a nacionalização do Direito

30 United Nations Human Rights Special Procedures. Framework Principles on Human Rights and the Environment: the main human rights obligations relating to the enjoyment of a safe, clean, healthy and sustainable environment. 2018. Available at: https:// www.ohchr.org/Documents/Issues/Environment/SREnvironment/FrameworkPrinciplesUserFriendlyVersion.pdf. Accessed on February 27, 2020.

31 KNOX, John. The Global Pact for the Environment: At the crossroads of human rights and the environment. Review of European, Comparative and International Environmental Law, 28(1), 2019, pp. 40-47.

32 A Corte Interamericana, por exemplo, não tem competência explícita, mas tem decidido em casos com repercussões ambientais, principalmente por meio do argumento do dano em ricochete. Para jurisprudência, veja, e.g.: Afro-Descendant Communities Displaced from the Cacarica River Basin (Operation Genesis) V. Colombia (2013); Kichwa Indigenous People of Sarayaku V. Ecuador (2012); Case of the Saramaka People v. Suriname (2007); Case of the Mayagna (Sumo) Awas Tingni Community v. Nicaragua (2001). Veja também: Mazzuoli and Teixeira (2013) De modo semelhante, na Corte Europeia de Direitos Humanos, veja e.g.: López Ostra vs. Spain (1994); Öneryildiz v. Turkey (2004); Guerra and Others v. Italy (1998); Taşkin and Others V. Turkey (2004); Powell and Rayner V. The United Kingdom (1990); Hatton and Others V. The United Kingdom (2003); Fadeyeva v. Russia (2005); Dzemyuk v. Ukraine (2014). O caso do sistema africano é um pouco diferente, já que o artigo 21 da Carta Africana dos Direitos das Pessoas prevê o direito humano à utilização dos recursos naturais. Embora com uma abordagem antropocêntrica, isso permite que a Comissão e a Corte avaliem questões ambientais diretamente. Assim foi, por exemplo, com o caso Ogoni People v. Nigeria (2002).
Internacional também é muito importante para a implementação das previsões internacionais. Eles são similares aos processos em andamento nas cortes internacionais de direitos humanos, evoluindo rumo a uma maior proteção ambiental, conforme demonstram os casos de litigância climática ${ }^{33}$.

Dessa síntese percebe-se, portanto, que a primeira dificuldade em se aplicar uma teoria de direitos humanos a deveres humanos de proteção ambiental no contexto internacional é a falta de reconhecimento explícito do direito ao meio ambiente equilibrado como direito humano. Propõe-se neste artigo, no entanto, a compreensão de que, mesmo que ainda implicitamente - o que impõe diversas restrições -, o direito ao meio ambiente equilibrado já é, para diversos efeitos, um direito humano. Para aqueles ainda desconfortáveis em aceitar essa compreensão, propõe-se, alternativamente, a antecipação de que tal reconhecimento é iminente.

Partindo-se dessa compreensão, então, o passo seguinte é analisar a viabilidade de adaptação da Teoria da Horizontalidade dos Direitos Humanos para os deveres humanos.

Conforme já consolidado na doutrina jurídica nacional, a Teoria da Horizontalidade dos Direitos Fundamentais confere aplicabilidade aos direitos fundamentais entre os particulares, isto é, para além da relação vertical entre Estado e indivíduos. Essa expansão operacional foi essencial para uma maior eficácia dos direitos fundamentais. ${ }^{34}$

No que tange à horizontalidade dos deveres fundamentais no âmbito nacional, a compreensão tampouco é difícil. A própria construção do conceito ${ }^{35}$ de deveres

\section{Disponível em, e.g.}

Urgenda Case (Supreme Court of the Netherlands, 2019)

ESPINER, Tom. Climate campaigners win Heathrow expansion case. 27 fev. 2020. Disponível em:

https://www.bbc.com/news/business-51658693. Acesso 27 fev. 2020.

CARRINGTON, Damian. Heathrow third runway ruled illegal over climate change. 27 fev. 2020. Disponível em: https://www.theguardian. com/environment/2020/feb/27/heathrow-third-runwayruled-illegal-over-climate-change. Acesso em: 27 fev. 2020.

34 Sobre a discussão acerca de eficácia dos direitos fundamentais, disponível também em:

RODRIGUES, Leandro Nascimento; LEAL, Pastora do Socorro Teixeira. A eficácia dos direitos fundamentais nas relações privadas à luz da jurisprudência do STF: análise crítica do RE 201. 819-8 e ADI 4815. Revista de Direitos e Garantias Fundamentais, v. 19, n.2 (2018). pp. 11-42.

35 GONÇALVES, Luísa Cortat Simonetti; FABRIZ, Daury César. 
fundamentais foi pensada justamente para a imposição de deveres a particulares. Isso quer dizer, naturalmente, deveres perante o Estado ${ }^{36}$, mas também deveres perante outros indivíduos ${ }^{37}$ e deveres perante a coletividade ${ }^{38}$, como é o caso dos deveres de proteção ambiental ${ }^{39}$. E isso quer dizer deveres impostos não apenas a particulares individuais, mas também empresas ${ }^{40}$. Duque e

Dever Fundamental: a construção de um conceito. In: DE MARCO, Christian Magnus; et al. Série Direitos Fundamentais Civis: teoria geral e mecanismos de efetividade no Brasil e na Espanha - tomo I. Joaçaba: editora Unoesc, 2013.

36 Por exemplo, deveres tributários:

SIQUEIRA, Julio Pinheiro Faro Homem de. Políticas públicas, deveres fundamentais e concretização de direitos. Revista Brasileira de Politicas Públicas, v. 3, n. 2, 2013. pp. 250-269.

TAVARES, Henrique da Cunha; PEDRA, Adriano Sant'Ana. Accessory Tax Obligations from the Perspective of the Fundamental Duties Theory. Congresso IV R. Belo Horizonte, 2013 (disponibilizado pelos autores).

37 Por exemplo, deveres dos descendentes para com os ascendentes:

GONÇALVES, Luísa Cortat Simonetti; FABRIZ, Daury César. A medida do binômio necessidade-possibilidade no dever fundamental dos descendentes de proverem os ascendentes. Derecho y Cambio Social, n. 31, 2013.

38 No que se inserem, por exemplo, o dever de colaborar com a Justiça

BUARQUE, Rodrigo Costa; PEDRA, Adriano Sant'Ana. A Recusa das Partes à Audiência Preliminar no Novo Código de Processo Civil: Necessidade de Motivação ante o Dever de Cooperação com a Justiça. Revista Magister de Direito Civil e Processual Civil, n. 72, 2016. pp. 112-123.

e até mesmo o dever de desobediência civil

PEDRA, Adriano Sant'Ana; BERGER, Rosa Elena Krause. O dever fundamental de desobedecer diante de um governo corrupto e opressivo. Revista Brasileira de Estudos Politicos, n. 116, 2018. pp. 11-62. GONÇALVES, Luísa Cortat Simonetti; PEDRA, Adriano Sant'Ana. Obediência ou Proteção? O que exigir do servidor público em caso de norma ambiental menos protetiva. Revista Direito e Liberdade, v. 22, n. 1, 2020.

39 Disponível em, e.g.:

BRIOSCHI, Livia; GONÇALVES, Luísa Cortat Simonetti; PEDRA, Adriano Sant'Ana. Dever Internacional de Reciclagem dos Resíduos Plásticos pelos Navios. Revista Foz, v.2, n. 2, 2019. pp. 71 88.

ABREU, Ivy de Souza; FABRIZ, Daury César. O Dever Fundamental de Proteção do Meio Ambiente e seu Fundamento na Solidariedade: uma análise à luz do holismo ambiental. Derecho y Cambio Social, n. 31, 2014. pp. 1-13.

40 Disponível em, e.g.:

GONÇALVES, Luísa Cortat Simonetti. Empreendedorismo Particular e Dever Fundamental de Diagnosticar e Planejar: uma análise no contexto jurídico brasileiro. Revista de Direito Ambiental, v. 89, 2018.

COLNAGO, Cláudio de Oliveira Santos; PEDRA, Adriano Sant'Ana. Los Deberes de los Proveedores de Servicios de Internet en el Medio Ambiente Digital: el caso del derecho de réplica en el Brasil. Estudios Constitucionales, n. 2, 2016. pp. 347-364.
Pedra ${ }^{41}$ inclusive descrevem a necessidade de horizontalidade nos deveres fundamentais como meio de concretização da solidariedade jurídica.

Não haveria também, assim, nenhum impedimento à eficácia horizontal dos deveres humanos. No entanto, assim como para os direitos humanos, essa horizontalidade ganha uma formatação distinta no âmbito internacional, onde as cadeias de relações são diferentes. Então, "a horizontalidade das normas do direito internacional reflete a inexistência de uma cadeia tal de valores, de modo que cada esfera constrói sua própria escala de valores para aplicação nos casos concretos de acordo com os mecanismos de governança prevalentes entre os atores que dela fazem parte". ${ }^{42}$

Por fim, resta apenas o óbice da situação ainda incerta das empresas multinacionais no Direito Internacional. Por exemplo, elas são, sem dúvidas, atores de direito internacional, mas não são sujeitos de direito internacional. Em grande parte, é justamente por essa dicotomia que a possibilidade de imposição de obrigações internacionais às empresas ainda é muito controversa. Controversa, mas não impossível, conforme se verá nos tópicos a seguir.

Portanto, conclui-se que a eficácia horizontal dos deveres fundamentais é, sim, uma forma mediata de imposição de obrigações às empresas no âmbito internacional.

\section{Inesperadas consequências hard para instrumentos soft}

É impossível tratar da possibilidade de imposição de deveres humanos a empresas no Direito Internacional sem se falar da responsabilidade corporativa ${ }^{43}$ (CSR, na sigla em inglês). Inicia-se esse tópico, então, com um breve intercurso histórico no tratamento jurídico dado à CSR pelo direito internacional. ${ }^{44}$

\footnotetext{
41 DUQUE, Bruna Lyra; PEDRA, Adriano Sant'Ana. Os Deveres Fundamentais e a Solidariedade nas Relações Privadas. Revista de Direitos Fundamentais e Democracia, v. 14, n. 14, 2013. pp. 147-161.

42 SILVA, Elaini Cristina Gonzaga. A Expansão do Direito Internacional: Uma Questão de Valores. Tese (Doutorado) Faculdade de Direito da Universidade de São Paulo, 2011. p. 31.

43 Também tratada como Responsabilidade Social Corporativa, Responsabilidade Ambiental Corporativa ou Responsabilidade Socioambiental Corporativa, todas consideradas sinônimos neste estudo.

44 A soft law tem importantíssimo papel também na formação do
} 
Já na década de 1950, definiu-se que "CSR se refere à obrigação dos empresários de buscar as políticas, tomar as decisões, ou seguir as linhas de ação que são desejáveis em termos dos objetivos e valores da nossa sociedade". ${ }^{45}$ É o início do entendimento de que as empresas têm obrigações para além das exigências estritamente legais, principalmente no cenário internacional, em que os desafios para a criação de obrigações diretamente para elas são maiores. É também o Princípio da Superação de Percepção de que o propósito de lucro das empresas é incompatível com preocupações socioambientais. Na década de 1970, Friedman ${ }^{46}$ fez a discussão retroagir um pouco, afirmando que a responsabilidade dos negócios é maximizar lucros em conformidade com as regras básicas da sociedade, tanto aquelas provenientes de lei quanto as de costumes éticos.

O direito internacional direcionou os primeiros esforços relativamente às empresas multinacionais em 1972, quando as Nações Unidas convocaram "a formação de um grupo de pessoas eminentes para estudar o impacto das corporações multinacionais no desenvolvimento econômico e nas relações internacionais" ${ }^{47}$. Em 1982, o grupo entregou uma versão preliminar de um código de regulação de investimentos internacionais endereçados a Estados e a empresas transnacionais (TNCs). No entanto, a ideia foi oficialmente abandonada em $1993 .^{48}$

direito ambiental. Nesse sentido, disponível em, e.g.: SOUZA, Leonardo da Rocha de Souza; LEISTER, Margareth Anne. A influência da soft law na formação do direito ambiental. Revista de Direito Internacional, Brasília, v. 12, n. 2, 2015 p. 767-784.

45 Tradução livre. No original: "CSR refers to the obligation of businessmen to pursue those policies, to make those decisions, or to follow those lines of action which are desirable in terms of the objectives and values of our society".

BOWEN, Harold R. Social responsibility of the businessman. New York: Harper \&amp; Row, 1953.

46 FRIEDMAN, Milton. The Social Responsibility of Business is to Increase its Profits. The New York Times Magazine, September 13, 1970. Disponível em: https://www.colorado.edu/studentgroups/libertarians/issues/friedman-soc-resp-business.html Acesso em: 13 abr. 2018.

47 "calling for the formation of a Group of Eminent Persons 'to study the impact of multinational corporations

on economic development and international relations"'.

MORAN, Theodore H. The United Nations and transnational corporations: a review and a perspective. Transnational Corporations. Ago. 2009, Vol. 18, No. 2. p. 91-112.

Disponível também em:

SAGAFI-NEJAD, Tagi. The UN and Transnational Corporations: From Code of Conduct to Global Compact. Bloomington and Indianapolis: Indiana University Press, 2008.

48 BERNAZ, Nadia. International soft law initiatives on business
Por isso, a primeira medida mais concreta veio apenas quase três décadas depois dos primeiros esforços, em 1996. No Pacto Global da ONU, as empresas signatárias assumem o compromisso de seguir dez princípios nas áreas de direitos humanos, trabalho, meio ambiente e anticorrupção. Eles foram derivados ${ }^{49}$ da Declaração Universal dos Direitos Humanos, da Declaração da Organização Internacional do Trabalho sobre os Princípios e Direitos Fundamentais no Trabalho, ${ }^{50}$ da Declaração do Rio sobre Meio Ambiente e Desenvolvimento, ${ }^{51}$ e da Convenção das Nações Unidas contra a Corrupção. Por isso, são princípios considerados universais.

O Pacto Global não é se pretende regulatório, mas sim uma plataforma para diálogo entre companhias. "Além dos compromissos feitos pela empresa de respeitar os princípios, e o leve mecanismo de monitoramento [...], o ponto central do Pacto Global é oferecer uma plataforma para as companhias trocarem boas práticas" ${ }^{\prime 2}$. Portanto, mesmo com esse passo adiante, a discussão sobre um rascunho sobre as responsabilidades das TNCs continuou suspensa.

Em 1997 surgiu uma subcomissão (atual Conselho de Direitos Humanos), "com a tarefa de preparar um documento sobre a questão da relação entre o gozo dos direitos humanos e os métodos de trabalho e as atividades das companhias transnacionais". ${ }^{53}$ A subcomis-

and human rights. In: BERNAZ, Nadia (ed.). Business and Human Rights. London: Routledge, 2017. pp. 164 - 207.

49 UNITED NATIONS GLOBAL COMPACT. The power of principles: Sustainability begins with aprinciples-based approach to doing business. Disponível em: https://www.unglobalcompact.org/whatis-gc/mission/principles. Acesso em: 11 abr. 2018.

50 OIT - Organização Internacional do Trabalho. Declaração da OIT sobre os Princípios e Direitos Fundamentais no Trabalho. 1998. Disponível em: https://www.ilo.org/public/english/standards/declaration/declaration_portuguese.pdf Acesso em: 30 abr. 2019.

51 ONU - Organização das Nações Unidas. Declaração do Rio de Janeiro sobre Meio Ambiente e Desenvolvimento (Carta do Rio). 1992. Disponível em: http://portal.iphan.gov.br/uploads/ ckfinder/arquivos/Carta\%20do\%20Rio\%201992.pdf . Acesso em: 27 maio 2019.

52 Tradução livre. No original: "Besides the commitment made by the company to respect the principles, and the light monitoring mechanism [...], the main point of the Global Compact is to provide a platform for companies to exchange good practices".

BERNAZ, Nadia. International soft law initiatives on business and human rights. In: BERNAZ, Nadia (ed.). Business and Human Rights. London: Routledge, 2017. pp. 164 - 207. p. 179.

53 Tradução livre. No original: "with the task of preparing a document on the question of the relationship between the enjoyment of human rights and the working methods and activities of transnational companies". 
são elaborou as chamadas Normas, mas, apresentadas em 2004, não foram aceitas pela Comissão de Direitos Humanos, já que embasaram-se na controversa ideia de que empresas poderiam ter obrigações perante o direito internacional.

Em 2005, a Secretaria Geral da ONU apontou, então, um representante especial para negócios e direitos humanos. John Ruggie, que também participou da equipe que estruturou o Pacto Global, conduziu um extenso processo consultivo, buscando consenso a respeito do tópico. ${ }^{54} \mathrm{O}$ resultado foi o quadro de referência "Proteger, Respeitar, Remediar", ${ }^{5}$ em 2008, embasado nesses três pilares interrelacionados unanimemente aceitos pelo Conselho de Direitos Humanos da ONU. ${ }^{56}$

A continuidade do processo consultivo com base nos pilares permitiu a elaboração dos "Princípios Orientadores sobre Empresas e Direitos Humanos: Implementando o Quadro de Referência das Nações Unidas 'Proteger, Respeitar e Remediar"', endossados pelo Conselho de Direitos Humanos da ONU em 2011. Eles são considerados parte da soft law no que tange às previsões destinadas às empresas e parte da hard law para as previsões destinadas aos Estados. A Organização para a Cooperação Econômica e o Desenvolvimento (OCDE) incorporou tais diretrizes por meio do anexo à Declaração sobre Investimento Internacional e as Empresas Multinacionais - as linhas diretrizes da OCDE para empresas multinacionais. Em 2011, essas diretrizes foram atualizadas e passaram a ter um foco mais abrangente em direitos humanos e a se alinhar com os princípios orientadores da ONU.

Percebe-se, então, que as questões em torna da responsabilidade se tornaram mais evidentes a partir da evolução do conceito de CSR. De uma perspectiva ju-

BERNAZ, Nadia. International soft law initiatives on business and human rights. In: BERNAZ, Nadia (ed.). Business and Human Rights. London: Routledge, 2017. pp. 164 - 207. p. 185.

54 BERNAZ, Nadia. International soft law initiatives on business and human rights. In: BERNAZ, Nadia (ed.). Business and Human Rights. London: Routledge, 2017. pp. 164 - 207. p. 191.

55 RUGGIE, John Gerard. Promotion and Protection of All Human Rights, Civil, Political, Economic, Social and Cultural Rights, Including the Right to Development - Protect, Respect and Remedy: a Framework for Business and Human Rights. April 7 th, 2008. Disponível em: https://www.businesshumanrights.org/sites/default/files/reportsand-materials/Ruggie-report-7-Apr-2008.pdf. Acesso em: 11 abr. 2018.

56 BERNAZ, Nadia. International soft law initiatives on business and human rights. In: BERNAZ, Nadia (ed.). Business and Human Rights. London: Routledge, 2017. pp. 164 - 207. p. 193. rídica, o uso desse termo traria consigo uma série de definições correlatas e de consequências. No entanto, o próprio Ruggie ${ }^{57}$ esclareceu que o uso do termo responsabilidade no contexto da CSR na verdade criou uma nova categoria de normas. Entre a moral clássica e as normas jurídicas haveria as normas sociais. Em síntese, a palavra responsabilidade não deveria ser interpretada em seu conceito jurídico, mas em seu sentido social, usual.

Da mesma forma, abordagens mais recentes ${ }^{58}$ consideram que normas voluntárias são, apenas, uma parte da CSR, e que o formato da norma é, na verdade, irrelevante. Conforme estruturado por McBarnet, ${ }^{59}$ a CSR pode significar agir além da lei, por meio da lei, pela lei, ou até mesmo contra a lei. A CSR “além da lei" incorpora as pressões da sociedade civil, mudanças de expectativas de consumidores e investidores, reações pós-escândalo, valores e cultura organizacionais, ou casos de negócio com vantagens competitivas. CSR "por meio da lei" é a implementação da CSR por meio das várias formas de regulação oficiais ${ }^{60}$. CSR "pela lei" também pode ir "além da lei", mas significa cumprir com seu espírito e complementar o campo jurídico da CSR, o qual tem suas limitações. A CSR “contra a lei” é defendida em sistemas jurídicos nos quais a CSR pode ser vista como contrária à lei por ser interpretada como um descumprimento do dever administrativo de maior lucratividade. ${ }^{61}$

57 RUGGIE, John Gerard. The Social Construction of the UN Guiding Principles on Business and Human Rights. Corporate Responsibility Initiative Working Paper No. 67. Cambridge, MA: John F. Kennedy School of Government, Harvard University. Jun. 2017. p. 13-15.

58 Sobre as discussões conceituais e de implementação da CSR, disponível também em:

FACHIN, Melina Girardi. Empresas e direitos humanos: compartilhando valor e responsabilidades. Revista de Direito Internacional, Brasília, v. 17, n. 1, 2020 p.324-339.

MORAIS, Dulce Teresinha Barros Mendes de. O papel do direito no contexto do desenvolvimento sustentável: uma avaliação qualitativa de programas corporativos de responsabilidade socioambiental. Revista de Direito Internacional, Brasília, v. 9, n. 3, 2012, p. 141-158.

59 MCBARNET, Doreen. Corporate social responsibility beyond law, through law, for law: the new corporate accountability. In: MCBARNET, Doreen; VOICULESCU, Aurora; and CAMPBELL, Tom (eds). The New Corporate Accountability. Corporate Social Responsibility and the Law, Cambridge: Cambridge University Press 2007. pp. 1-56.

${ }^{60}$ Por exemplo, hard law nacionais e internacionais, soft law nacionais e internacionais, auto-regulação,

ou meta-regulação.

${ }_{61}$ Empresas anglo-americanas tendem a usar essa perspectiva, enquanto a abordagem dos stakeholders 
Uma das principais críticas aos modelos de CSR é a uma suposta ausência de consequências ao descumprimento. Ela advém do fato de que os documentos sobre CSR bem como os desenvolvimentos teóricos acerca do tema ainda constituem a chamada soft law no direito internacional. Isso significa a manutenção do caráter não vinculante, apesar de toda a evolução ocorrida. Entretanto, isso não significa, necessariamente, ineficácia.

A essência da crítica contra essa natureza não vinculante é que ela leva à inexistência de consequências jurídicas: "embora os modelos de CSR ainda sejam muito populares, sua eficiência é questionada na perspectiva jurídica, já que não são juridicamente executáveis e contam simplesmente com a boa vontade das empresas". ${ }^{62}$ Tais abordagens, normalmente, andam em conjunto com as críticas contra as iniciativas que dependem de relatórios feitos pelas empresas, já que esse é o formato normativo voluntário mais comum. Relatórios, mesmo quando obrigatórios, se embasam na conscientização e na regulação por meio de atores de mercado. Assim, mesmo quando obrigatórios, os relatórios constituem ferramenta muito parecida com as voluntárias. Nesse sentido alguns autores dizem que “já que todas essas iniciativas ainda são seletivas e os critérios para elaboração dos relatórios ainda são vagos, elas não são formas eficientes de forçar as empresas a agir responsavelmente". ${ }^{63}$

alemães levanta questões diferentes.

MCBARNET, Doreen. Corporate social responsibility beyond law, through law, for law: the new corporate accountability. In: MCBARNET, Doreen; VOICULESCU, Aurora; and CAMPBELL, Tom (eds). The New Corporate Accountability. Corporate Social Responsibility and the Law, Cambridge: Cambridge University Press 2007. pp. 1-56. p. 23

${ }^{62}$ Tradução livre. No original: "even though the CSR models are still very popular, the efficiency of these

models is questioned from a legal perspective, as they are not legally enforceable and simply rely on the

goodwill of the companies".

EROGLU, Yrd. Doç Dr. Muzaffer. How to Achieve Sustainable Companies: Soft Law (Corporate Social Responsibility and Sustainable Investment) or Hard Law (Company Law). Kadin Has Universitesi, Hukuk Fakultesi Dergisi, Haziran 2014, Cilt: 2 - Say 1:1. pp. 87-108. p. 89.

63 Tradução livre. No original: "since almost all these initiatives are still selective and reporting criterias are

vague, it is not an efficient ways to force companies to act responsible" (sic).

EROGLU, Yrd. Doç Dr. Muzaffer. How to Achieve Sustainable Companies: Soft Law (Corporate Social Responsibility and Sustainable Investment) or Hard Law (Company Law). Kadin Has Universitesi, Hukuk. Fakultesi Dergisi, Haziran 2014, Cilt: 2 - Say 1:1. pp. 87-108. p. 94.
Há alguns problemas com essa linha de argumentação crítica, os quais são divididos em três principais. $\mathrm{O}$ primeiro é que a CSR vem como uma crítica contra o formato legal tradicional e positivista, que já se mostrou incapaz de lidar com as externalidades globais. Portanto, usar o mesmo formato para criticar a CSR cria um paradoxo difícil de ser superado, já que significa uma impossibilidade lógica. Partir dessa perspectiva poderia significar adentrar em uma argumentação circular e, logo, infrutífera. O segundo problema é que essa crítica adota, implicitamente, um conceito que está sendo progressivamente superado, isto é, o conceito que entende a CSR como conjunto de normas voluntárias. Conforme discutido anteriormente, nem todas as ferramentas e abordagens de CSR são voluntárias e/ou não vinculantes. Consequentemente, endereçar uma crítica contra tal natureza como uma crítica contra a própria CSR é uma falácia de composição ${ }^{64}$. O terceiro problema é que essa crítica parece esquecer a razão básica pela qual a CSR foi concebida: a existência de uma lacuna de governança. Isso significa que a lei ou regulações puramente estatais carecem das ferramentas para enfrentar a questão das externalidades transnacionais. Nesse sentido, é ilógico encarar essas mesmas ferramentas insuficientes dentro da regulação estatal, sem auxílio externo. Ademais, a principal razão para essa lacuna é a complexidade do contexto. Uma das razões para essa complexidade é a carência de informações técnicas, que muitas vezes apenas as empresas detêm. Logo, convidar as corporações para, voluntariamente, se unir aos esforços é, também, uma estratégia para acessar as informações faltantes.

Independentemente desses problemas estruturais identificados na crítica contra a não vinculatividade da CSR, mesmo se a meta for uma abordagem mais tradicional do direito, com antecedentes e consequentes claramente definidos, a crítica não é totalmente verdadeira. A literatura acadêmica e alguns estudos de caso indicam um movimento rumo a mecanismos que transformam instrumentos inicialmente voluntários em instrumentos exequíveis. ${ }^{65} \mathrm{Uma}$ das formas de fazer cumprir a CSR é

\footnotetext{
${ }^{64}$ Uma falácia de composição acontece quando o argumento considera uma característica verdade para

o todo só porque ela é verdade para uma parte.

65 Sobre os progressivos efeitos hard de documentos soft, disponível também em:

NIEUWENKAMP, Roel. The OECD Guidelines for Multinational Enterprises on Responsible Business Conduct: Soft Law with Hard Consequences. DQ. December 2013, No. 4.

NOLAN, Justine. Hardening soft law: are the emerging corporate
} 
por meio do direito privado, a qual é justamente o foco deste tópico ${ }^{66}$.

Um caminho são previsões contratuais, por exemplo em contratos unilaterais com fornecedores. Este permite, inclusive, efeitos transfronteiriços, posto que compõem o direito internacional privado e criam normas entre as partes, independentemente de sua localização geográfica. Outro caminho é considerar como prática comercial desleal no direito do consumidor o momento em que uma empresa anuncia práticas autorregulatórias de CSR, mas não as cumpre. ${ }^{67}$ Este, apesar de aplicável exclusivamente pelo direito nacional, pode ser indiretamente aproveitado pelo direito internacional público ao estabelecer diretrizes para que os Estados as transponham nacionalmente, ou até mesmo pelo direito internacional privados, por meio dos contratos, conforme descrito no caminho anterior. Por fim, há possibilidades dentro do direito penal, se descumprido o dever de cuidado. Esse último caminho não parece, no entanto, abrir possibilidades para o direito internacional.

Depreende-se desse tópico, em breve síntese, que,

social disclosure laws capable of generating substantive compliance with human rights? Revista de Direito Internacional, Brasília, v. 15, n. 2, 2018 p. 64-83.

${ }^{66}$ Nesse sentido, disponível em, e.g.:

MITKIDIS, Katerina. Peterkova. Sustainability Clauses in International Supply Chain Contracts: Regulation, Enforceability and Effects of Ethical Requirements. Nordic Journal of Commercial Law 2014/1, pp. 1-30.

PONCIBOे, Cristina. The Contractualization of Environmental Sustainability. European Review of Contract Law, (2016) Vol. 12, No. 4, pp. 335-355.

BECKERS, Anna. Enforcing corporate social responsibility codes: On global self-regulation and national private law (International studies in the theory of private law, volume 12). Oxford: Hart Publishing, 2015.

BECKERS, Anna. The Regulation of Market Communication and Market Behaviour: Corporate Social Responsibility and the Directives on Unfair Commercial Practices and Unfair Contract Terms. Common Market Law Review (2017) Vol. 54, No. 2.

EIJSBOUTS, Jan. Corporate Codes as Private Co-Regulatory Instruments in Corporate Governance and Responsibility and Their Enforcement. Indiana Journal of Global Legal Studies, 2017, 24(1), pp. 181-205.

DAM, Cees van. Enhancing Human Rights Protection: A Company Lawyer's Business. Inaugural Lecture Rotterdam School of Management, Erasmus University, 18 September 2015.

67 Diferentes países já possuem jurisprudência considerando como prática comercial desleal quando as

empresas descumprem compromissos assumidos em seus códigos de conduta. Disponível em, por exemplo, Kasky vs. Nike (EUA Suprema Corte da Califórnia), Verbraucherzentrale Hamburg vs. Lidl (Alemanha), e decisões de autoridades consumeristas contra a Volkswagen na Itália, na Holanda e nos EUA. apesar da clássica divisão do direito internacional entre normas vinculantes (hard law) e normas não vinculantes (soft law), cada vez mais, as normas não vinculantes que envolvem obrigações para empresas produzem efeitos vinculantes inicialmente não planejados ou previstos. Em se tratando de empresas, essas consequências se tornam ainda mais interessantes, pois, conforme visto, ainda há resistência à imposição de obrigações a esses entes por meio do direito internacional, sem que sejam reconhecidos como sujeitos de direito internacional. No que tange, especificamente, à constituição de deveres humanos internacionais, tais obrigações podem ser assim classificadas em virtude de seu conteúdo e dos bens que visam proteger, visto que, ao tratarmos de CSR, estamos falando da responsabilidade das empresas relativamente aos direitos humanos dos stakeholders e à proteção ambiental.

\section{Previsão de obrigações para empresas em instrumentos internacionais hard law: o exemplo da convenção da basileia}

Apesar de toda a controvérsia e da falta de definição teórico-jurídica para a imposição de obrigações - e deveres humanos - a empresas no âmbito internacional, há iniciativas que se lançam ao largo dessas discussões. ${ }^{68}$ Um exemplo recente é a emenda sobre plásticos à Convenção da Basileia.

A Convenção da Basileia é a única convenção internacional vinculante referente ao movimento global de resíduos. ${ }^{69}$ Ela entrou em vigor no dia 5 de março de 1992 e tem 187 partes. Enquanto instrumento clássico do direito internacional público, a Convenção vincula, logicamente, os Estados que dela são signatários. Um de seus aspectos mais relevantes é a abordagem opera-

\footnotetext{
68 A análise aqui em questão vai além dos efeitos produzidos após a transposição das normas de direito internacional para o direito interno. No sentido dessa última questão, disponível em, e.g.: CARVALHO, Alexander Perazo Nunes de. Convencionalização do direito civil: a aplicação dos tratados e convenções internacionais no âmbito das relações privadas. Revista de Direito Internacional, Brasília, v. 12 , n. 2,2015 p. 341-354.

69 GROSZ, Mirina. Sustainable Waste Trade Under WTO Law: Chances and Risks of the Legal Frameworks' Regulation of Transboundary Movements of Wastes. Boston: Martinus Nijhoff Publishers, 2011. p. 20.
} 
cional ${ }^{70}$ da definição de resíduos que traz, em seu artigo 2(1): “por 'resíduos' se entendem as substâncias ou objetos, cujo depósito se procede, se propõe proceder-se, ou se está obrigado a proceder-se em virtude do disposto na legislação nacional". ${ }^{71}$ Ela segue categorizando os resíduos em perigosos e outros, desde que a Convenção surgiu no contexto de um crescimento avassalador dos resíduos perigosos gerados anualmente no planeta. ${ }^{72} \mathrm{O}$ foco não é somente nos resíduos perigosos, mas também nos impactos que os seus movimentos globais poderiam ter no mundo em desenvolvimento. Essa preocupação está presente no preâmbulo (parágrafo 7), embora acrescida em 1995, durante a COP 3: "reconhecendo também o desejo crescente de proibir movimentos transfronteiriços de resíduos perigosos e seu depósito em outros Estados, especialmente nos países em desenvolvimento" ${ }^{73}$

Há diversos aspectos interessantes sobre o conteúdo e a eficácia da Convenção, mas, para o presente estudo, importa destacar que os signatários e, portanto, legalmente vinculados, da Convenção são os países dela signatários. No entanto, emenda recentemente aprovada para combater a poluição plástica trouxe inovação instigante para as discussões sobre imposição de deveres internacionais a empresas.

Em junho de 2018, o governo norueguês propôs uma emenda sobre o tratamento de plásticos, que foi adotada na COP14, em maio de 2019. As mudanças entrarão em vigor em $1^{\circ}$ de janeiro de 2021 e estabelecem cuidados especiais para o comércio transfronteiriço de rejeitos plásticos. "Após a entrada em vigor desses Ane-

70 GROSZ, Mirina. Sustainable Waste Trade Under WTO Law: Chances and Risks of the Legal Frameworks' Regulation of Transboundary Movements of Wastes. Boston: Martinus Nijhoff Publishers, 2011. p. 21.

71 United Nations Environmental Program - UNEP. Basel Convention on the Control of Transboundary Movements of Hazardous Wastes and their Disposal. 1989. Disponível em: https://www.basel.int/Portals/4/Basel\%20Convention/docs/text/BaselConventionText-e. pdf Acesso em: 28 set. 2019.

UNEP - Basel Convention. Milestones. 2019. Available at: http:// basel.int/TheConvention/ Overview/Milestones/tabid/2270/Default.aspx. Accessed on September 29, 2019.

72 HACKETT, David P. An Assessment of the Basel Convention on the Control of Transboundary Movements of Hazardous Waste and their Disposal. American University Journal of International Law and Policy, 5(2) ,1990, pp. 291-324. p. 294.

73 Convenção da Basileia Sobre o Controle de Movimentos Transfronteiriços de Resíduos Perigosos e seu Depósito (transposta pelo decreto n. 875/1993). 1997. Disponível em: http://www.planalto. gov.br/ccivil_03/decreto/D0875.htm Acesso em: 18 maio 2020. xos emendados, se uma empresa em qualquer um dos países membros pretender exportar tais resíduos, será necessária a obtenção de consentimento prévio e informado do país destinatário". ${ }^{74} \mathrm{Na}$ tabela 1 , apresenta-se um resumo das mudanças aprovadas:

\begin{tabular}{|l|l|l|}
\hline Anexos & Detalhes & $\begin{array}{l}\text { Destaques dos } \\
\text { anexos emen- } \\
\text { dados }\end{array}$ \\
\hline $\begin{array}{l}\text { Anexo II } \\
\text { (resíduos plásti- } \\
\text { cos controlados } \\
\text { no âmbito da } \\
\text { Convenção) }\end{array}$ & $\begin{array}{l}\text { Lista de "Ou- } \\
\text { tros Rejeitos" a } \\
\text { serem controla- } \\
\text { dos no âmbito } \\
\text { da Convenção }\end{array}$ & $\begin{array}{l}\text { Nova listagem } \\
\text { dos rejeitos } \\
\text { plásticos, com } \\
\text { exceção dos } \\
\text { listados nos } \\
\text { Anexos VIII e } \\
\text { IX. }\end{array}$ \\
\hline $\begin{array}{l}\text { Anexo VIII } \\
\text { (resíduos plásti- } \\
\text { cos controlados } \\
\text { no âmbito da } \\
\text { Convenção) }\end{array}$ & $\begin{array}{l}\text { Lista de exem- } \\
\text { plos de resíduos } \\
\text { perigosos }\end{array}$ & $\begin{array}{l}\text { Nova listagem } \\
\text { de resíduos } \\
\text { plásticos como } \\
\text { resíduos peri- } \\
\text { gosos que têm } \\
\text { características } \\
\text { perigosas iden- } \\
\text { tificadas, com } \\
\text { base no processo } \\
\text { de descarte ou } \\
\text { características } \\
\text { químicas }\end{array}$ \\
\hline $\begin{array}{l}\text { Anexo IX } \\
\text { (resíduos plásti- } \\
\text { cos controlados } \\
\text { no âmbito da } \\
\text { Convenção) }\end{array}$ & $\begin{array}{l}\text { Lista de exem- } \\
\text { plos de rejeitos } \\
\text { perigosos não } \\
\text { controlados } \\
\text { pela Convenção }\end{array}$ & $\begin{array}{l}\text { Esclarecimen- } \\
\text { tos adicionais } \\
\text { do escopo de } \\
\text { resíduos plásti- } \\
\text { cos limpos, que } \\
\text { são apropriados } \\
\text { para reciclagem }\end{array}$ \\
\hline
\end{tabular}

Tabela 1 - resumo das emendas adotadas na COP14 (maio, $2019)^{75}$

Além disso, a COP14 estabeleceu novas iniciativas para buscar soluções para a poluição plástica: (i) um

\footnotetext{
74 Japan Ministry of Economy, Trade and Industry - METI. Fourteenth Meeting of the Conference of the Parties to the Basel Convention (COP14) Held. May 14 ${ }^{\text {th }}$, 2019. Available at: https://www.meti.go.jp/ english/press/2019/0514_002.html. Accessed on September 29, 2019.

75 Japan Ministry of Economy, Trade and Industry - METI. Fourteenth Meeting of the Conference of the Parties to the Basel Convention (COP14) Held. May 14 ${ }^{\text {th }}$, 2019. Available at: https://www.meti.go.jp/ english/press/2019/0514_002.html. Accessed on September 29, 2019.
} 
grupo de trabalho deveria "discutir sobre a revisão das Diretrizes para Gerenciamento Ambientalmente Saudável de Resíduos Plásticos"; ${ }^{76}$ e (ii) uma Parceria sobre Resíduos Plásticos, para encorajar países membros a gerenciar os resíduos plásticos de uma forma ambientalmente correta", ${ }^{77}$ que participará de atividades para coletar dados e conscientizar o público, a partir de 2020.

Chama atenção, em especial, o estabelecimento de obrigação às empresas exportadoras de resíduos plásticos. Ela abre, inclusive, a possibilidade de estruturação de outras previsões no mesmo sentido após as discussões do grupo de trabalho e da parceria. No caso aqui descrito, ao contrário das discussões anteriores relativamente à criação de instrumentos específicos para vinculação de empresas em âmbito internacional sobre CSR, a emenda não levantou, pelo menos por enquanto, nenhuma resistência. Trata-se, portanto, de exemplo que demonstra a possibilidade de criação de obrigações - e, consequentemente, deveres humanos - para empresas no bojo do direito internacional, independentemente dos debates sobre seu status jurídico. Adicionalmente, as normas de comércio internacional parecem constituir meio particularmente propício para essa estruturação.

\section{Considerações finais}

O presente estudo enfrentou o questionamento se é possível estabelecer obrigações de proteção socioambiental para empresas multi e transnacionais com base no Direito Internacional Público e da teoria dos deveres fundamentais.

A fim de se chegar a uma resposta para questão tão complexa neste momento tão inicial das teorias, optamos por um corte mais próximo, por meio de casos específicos. Por isso enfrentamos três questões secundárias: (i) pode-se falar em horizontalidade de aplicação dos deveres humanos? (ii) seria possível derivar análo-

\footnotetext{
Japan Ministry of Economy, Trade and Industry - METI. Fourteenth Meeting of the Conference of the Parties to the Basel Convention (COP14) Held. May 14 ${ }^{\text {th }}$, 2019. Available at: https://www.meti.go.jp/ english/press/2019/0514_002.html. Accessed on September 29, 2019.

77 Japan Ministry of Economy, Trade and Industry - METI. Fourteenth Meeting of the Conference of the Parties to the Basel Convention (COP14) Held. May 14 ${ }^{\text {th }}$, 2019. Available at: https://www.meti.go.jp/ english/press/2019/0514_002.html. Accessed on September 29, 2019 .
}

gos internacionais de aplicações que têm sido utilizadas no âmbito nacional para vincular empresas a seus compromissos ambientais, como por meio do direito consumerista e do direito contratual? (iii) É possível impactar regras impostas às empresas privadas por meio de normas dirigidas aos Estados, como normas de comércio internacional?

Para todas as três perguntas secundárias, a resposta foi afirmativa e demonstrou significativos avanços recentes no sentido de passos progressivos rumo à imposição de deveres humanos a empresas no âmbito jurídico internacional.

No caso da horizontalidade, o próprio conceito dos deveres fundamentais já foi construído - primeiramente no contexto nacional brasileiro e depois expandido para o contexto internacional - voltando-se à aplicabilidade aos particulares. Assim, torna-se imediata e simples também a transposição da Teoria da Horizontalidade.

Já a utilização de contratos e do direito consumerista - e principalmente esta última - pode depender de auxílio do direito nacional. Entretanto, seu potencial chega ao núcleo deste estudo. Isto é, esse caminho detém potencial para influenciar o estabelecimento de deveres humanos às empresas no direito internacional.

Por fim, o exemplo da Convenção da Basileia demonstrou que, em algumas situações, pode até mesmo ser possível passar ao largo das discussões e resistências teóricas a essas imposições e inserir obrigações a empresas em instrumentos internacionais de hard law. Nesse caso, entretanto, ainda há de se aguardar a efetividade que o dispositivo demonstrará. Raciocínio semelhante pode ser empregado a normas de comércio internacional, as quais, embora tenham como destinatário os Estados, afetam, também, as partes privadas aí inseridas.

Por todo o exposto, a principal contribuição deste estudo é analisar - até onde sabemos, de forma inédita - as interconexões entre as potencialidades do direito internacional para imposição da CSR e os deveres humanos. Espera-se, assim, estar contribuindo para a formulação teórica das possibilidades de proteção internacional dos direitos humanos e do meio ambiente frente à atuação corporativa. 


\section{Referências}

ABREU, Ivy de Souza; FABRIZ, Daury César. O Dever Fundamental de Proteção do Meio Ambiente e seu Fundamento na Solidariedade: uma análise à luz do holismo ambiental. Derecho y Cambio Social, n. 31, 2014. pp. 1-13.

ALEGRE MARTÍNEZ, M. Á. Los deberes en la constitución española: esencialidad y problemática. Teoría y Realidad Constitucional, n. 23, 2009.

ALSTON, Philip; GOODMAN, Ryan. International Human Rights. Oxford: Oxford University Press, 2013.

ANTON, Donald K.; SHELTON, Dinah L. Environmental Protection and Human Rights. New York: Cambridge University Press, 2011.

BADERIN, Mashood A.; SSENYONJO, Manisuli. Development of International Human Rights Law Before and After the UDH. In: BADERIN, Mashood A.; SSENYONJO, Manisuli (eds.). International Human Rights Law: Six Decades after the UDHR and Beyond. Farnham: Ashgate, 2010. pp. 3-27.

BAYÓN MOHINO, J. C. Los deberes positivos generales y la determinación de sus límites (observaciones al artículo de Ernesto Garzón Valdés). Doxa, n. 3, 1986.

BECKERS, Anna. Enforcing corporate social responsibility codes: On global self-regulation and national private law (International studies in the theory of private law, volume 12). Oxford: Hart Publishing, 2015.

BECKERS, Anna. The Regulation of Market Communication and Market Behaviour: Corporate Social Responsibility and the Directives on Unfair Commercial Practices and Unfair Contract Terms. Common Market Law Review (2017) Vol. 54, No. 2.

BERNAZ, Nadia. International soft law initiatives on business and human rights. In: BERNAZ, Nadia (ed.). Business and Human Rights. London: Routledge, 2017. pp. 164 - 207. p. 175.

BOBBIT, Philip. A guerra e a paz na história moderna: o impacto dos grandes conflitos e da política na formação das nações. Rio de Janeiro: Campus, 2003.

BOWEN, Harold R. Social responsibility of the businessman. New York: Harper \& Row, 1953.
BRIOSCHI, Livia; GONÇALVES, Luísa Cortat Simonetti; PEDRA, Adriano Sant'Ana. Dever Internacional de Reciclagem dos Resíduos Plásticos pelos Navios. Revista Foz, v.2, n. 2, 2019. pp. 71-88.

BUARQUE, Rodrigo Costa; PEDRA, Adriano Sant'Ana. A Recusa das Partes à Audiência Preliminar no Novo Código de Processo Civil: Necessidade de Motivação ante o Dever de Cooperação com a Justiça. Revista Magister de Direito Civil e Processual Civil, n. 72, 2016. pp. 112-123.

CASTELO BRANCO, Patrícia Martins; DA SILVA, Fábio Luiz. História Moderna II. 1. ed. São Paulo: Pearson Prentice Hall, 2009.

CLAPP, Jennifer; DAUVERGNE, Peter. Brief History of International Environmental Cooperation. In: NICHOLSON, Simon; WAPNER, Paul (eds.). Global Environmental Politics: from person to planet. New York: Routledge, 2016, pp. 121-136.

COLNAGO, Cláudio de Oliveira Santos; PEDRA, Adriano Sant'Ana. Los Deberes de los Proveedores de Servicios de Internet en el Medio Ambiente Digital: el caso del derecho de réplica en el Brasil. Estudios Constitucionales, n. 2, 2016. pp. 347-364.

Convenção da Basileia Sobre o Controle de Movimentos Transfronteiriços de Resíduos Perigosos e seu Depósito (transposta pelo decreto n. 875/1993). 1997. Disponível em: http://www.planalto.gov.br/ccivil_03/ decreto/D0875.htm Acesso em: 18 maio 2020.

DAM, Cees van. Enhancing Human Rights Protection: A Company Lawyer's Business. Inaugural Lecture Rotterdam School of Management, Erasmus University, 18 September 2015.

DÍAZ REVORIO, F. J. Derechos humanos y deberes fundamentales. Sobre el concepto de deber constitucional y los deberes en la Constitución Española de 1978. Revista del Instituto de Ciencias Jurídicas de Puebla, v. 5, n. 28, 2011.

DI COSIMO, G. Dovere di difesa della patria, servizio militare, servizio civile. Archivio Pace Diritti Umani, Padova, p. 55-66, 09 nov. 2011.

DUDEK, Wanilton. Teoria do Estado Moderno: Leituras Econômicas e Culturalistas. Ensino e Pesquisa. Paraná, Maio 2008, v.1, n.5, pp. 6-16. 
DUPUY, Pierre-Marie; VIÑUALES, Jorge E. International Environmental Law. Cambridge: Cambridge University Press, 2015.

DUQUE, Bruna Lyra; PEDRA, Adriano Sant'Ana. Os Deveres Fundamentais e a Solidariedade nas Relações Privadas. Revista de Direitos Fundamentais e Democracia, v. 14, n. 14, 2013. pp. 147-161.

EBBESON, Jonas. The rule of law in governance of complex socio-ecological changes. Global Environmental Change 20(2010). pp. 414-422. p. 420

EHLE, Géssica Adriana; NASCIMENTO, Valéria Ribas do. A internacionalização do direito e o binômio "vida e morte": reflexões à luz da dignidade humana e de uma cultura cosmopolita. Revista de Direitos e Garantias Fundamentais, v. 18, n.2 (2017). pp. 227-246.

EIJSBOUTS, Jan. Corporate Codes as Private Co-Regulatory Instruments in Corporate Governance and Responsibility and Their Enforcement. Indiana Journal of Global Legal Studies, 2017, 24(1), pp. 181-205.

EROGLU, Yrd. Doç Dr. Muzaffer. How to Achieve Sustainable Companies: Soft Law (Corporate Social Responsibility and Sustainable Investment) or Hard Law (Company Law). Kadin Has Universitesi, Hukuk Fakultesi Dergisi, Haziran 2014, Cilt: 2 - Say 1:1. pp. 87-108.

FRIEDMAN, Milton. The Social Responsibility of Business is to Increase its Profits. The New York Times Magazine, September 13, 1970. Disponível em: https:// www.colorado.edu/studentgroups/libertarians/issues/ friedman-soc-resp-business.html Acesso em: 13 abr. 2018.

GARZÓN VALDÉS, E. Algunos comentarios críticos a las críticas de Juan Carlos Bayón y Francisco Laporta. Doxa, v. 3, 1986a.

GARZÓN VALDÉS, E. Los deberes positivos generales y su fundamentación. Doxa, v. 3, 1986b.

GLENDON, M.A. The Rule of Law in the Universal Declaration of the Human Rights. Northwestern Journal of International Human Rights, 2(1), 2004, article 5 [online]. Available on: https://scholarlycommons.law.northwestern.edu/cgi/viewcontent. cgi?article $=1008 \&$ co ntext $=$ njihr. Accessed on February $26,2020$.

GONÇALVES, Luísa Cortat Simonetti. Empreendedorismo Particular e Dever Fundamental de Diagnosticar e Planejar: uma análise no contexto jurídico brasileiro. Revista de Direito Ambiental, v. 89, 2018.
GONÇALVES, Luísa Cortat Simonetti. Legal Remedies against the Plastic Pollution of the Oceans: an analysis of the attempts from public international law and private initiatives to face the plastic soup. Bilt: Proefschriftmaken, 2020.

GONÇALVES, Luísa Cortat Simonetti; FABRIZ, Daury César. Dever Fundamental: a construção de um conceito. In: DE MARCO, Christian Magnus; et al. Série Direitos Fundamentais Civis: teoria geral e mecanismos de efetividade no Brasil e na Espanha - tomo I. Joaçaba: editora Unoesc, 2013.

GONÇALVES, Luísa Cortat Simonetti; FABRIZ, Daury César. A medida do binômio necessidade-possibilidade no dever fundamental dos descendentes de proverem os ascendentes. Derecho y Cambio Social, n. 31, 2013.

GONÇALVES, Luísa Cortat Simonetti; PEDRA, Adriano Sant'Ana. Obediência ou Proteção? O que exigir do servidor público em caso de norma ambiental menos protetiva. Revista Direito e Liberdade, v. 22, n. $1,2020$.

GONÇALVES, Luísa Cortat Simonetti; PEDRA, Adriano Sant'Ana. Direito Internacional dos Deveres Humanos: reflexões para uma teoria internacional envolvendo atores privados. 2019. (prelo)

GROSZ, Mirina. Sustainable Waste Trade Under WTO Law: Chances and Risks of the Legal Frameworks' Regulation of Transboundary Movements of Wastes. Boston: Martinus Nijhoff Publishers, 2011.

HACKET'T, David P. An Assessment of the Basel Convention on the Control of Transboundary Movements of Hazardous Waste and their Disposal. American University Journal of International Law and Policy, 5(2) ,1990, pp. 291-324.

Japan Ministry of Economy, Trade and Industry METI. Fourteenth Meeting of the Conference of the Parties to the Basel Convention (COP14) Held. May 14th, 2019. Available at: https://www.meti.go.jp/english/press/2019/0514_002.html. Accessed on September 29, 2019.

KNOX, John. The Global Pact for the Environment: At the crossroads of human rights and the environment. Review of European, Comparative and International Environmental Law, 28(1), 2019, pp. 40-47.

KOUBI, M. G. La déférence, un devoir sans droit? Communications, v. 69, p. 201-214, 2000. 
LAKATOS, Eva Maria; MARCONI, Marina de Andrade. Metodologia Científica. 5. ed. rev. ampl. São Paulo: Atlas, 2010.

LANCHESTER, F. Los deberes constitucionales en el derecho comparado. Revista de Derecho Constitucional Europeo, v. 7, n. 13, 2010.

LAPORTA, F. J. Algunos problemas de los deberes positivos generales (observaciones a un artículo de Ernesto Garzón Valdés). Doxa, n. 3, 1986.

MCBARNET, Doreen. Corporate social responsibility beyond law, through law, for law: the new corporate accountability. In: MCBARNET, Doreen; VOICULESCU, Aurora; and CAMPBELL, Tom (eds). The New Corporate Accountability. Corporate Social Responsibility and the Law, Cambridge: Cambridge University Press 2007. pp. 1-56.

MEADOWS Dennis et. al. Os Limites do Crescimento. Massachussets: Donella Meadows, 1972.

MENEZES NETO, Elias Jacob. As novas configurações da soberania em uma sociedade hiperconectada. Revista de Direitos e Garantias Fundamentais, v. 19, n.3 (2018). pp. 65-98.

MEYER-BISCH, P. Les devoirs de l'homme: de la réciprocité dans les droits de l'homme. Fribourg: Étidions Universitaires, 1989.

MITKIDIS, Katerina. Peterkova. Sustainability Clauses in International Supply Chain Contracts: Regulation, Enforceability and Effects of Ethical Requirements. Nordic Journal of Commercial Law 2014/1, pp. 1-30.

MORAN, Theodore H. The United Nations and ansnational corporations: a review and a perspective. Transnational Corporations. Ago. 2009, Vol. 18, No. 2. p. 91 112.

NABAIS, J. C. A face oculta dos direitos fundamentais: os deveres e os custos dos direitos. Revista Direito Mackenzie, São Paulo, ano 3, n. 2, p. 11-30, 2002.

NABAIS, J. C. Por uma liberdade com responsabilidade. Coimbra: Coimbra, 2007.

OIT - Organização Internacional do Trabalho. Declaração da OIT sobre os Princípios e Direitos Fundamentais no Trabalho. 1998. Disponível em: https://www. ilo.org/public/english/standards/declaration/declaration_portuguese.pdf Acesso em: 30 abr. 2019.
ONU - Organização das Nações Unidas. Declaração do Rio de Janeiro sobre Meio Ambiente e Desenvolvimento (Carta do Rio). 1992. Disponível em: http://portal. iphan.gov.br/uploads/ckfinder/arquivos/Carta $\% 20$ do\%20Rio\%201992.pdf . Acesso em: 27 maio 2019.

PALOMBELLA, G. De los derechos y de su relación con los deberes y los fines. Derechos y Libertades, $n$. 17, 2007.

PECES-BARBA MARTÍNEZ, G. Los deberes fundamentales. Doxa, n. 4, 1987.

PEDRA, Adriano Sant'Ana. A Importância dos Deveres Humanos na Efetivação de Direitos. In: ALEXY, Robert; et. al. (org.) Níveis de Efetivação dos Direitos Fundamentais Civis e Sociais: um diálogo Brasil e Alemanha. Joaçaba: Editora Unoesc, 2013. pp. 281-301.

PEDRA, Adriano Sant'Ana; BERGER, Rosa Elena Krause. O dever fundamental de desobedecer diante de um governo corrupto e opressivo. Revista Brasileira de Estudos Políticos, n. 116, 2018. pp. 11-62.

PIOVESAN, Flávia. Sistema Internacional de Proteção dos Direitos Humanos. I Colóquio Internacional de Direitos Humanos. São Paulo, Brasil, 2001. Available at: http://www.dhnet.org.br/direitos/sip/textos/a_pdf/ piovesan_sip.pdf. Accessed on: Octorber 26, 2016.

PONCIBÒ, Cristina. The Contractualization of Environmental Sustainability. European Review of Contract Law, (2016) Vol. 12, No. 4, pp. 335-355.

ROCA, V. ¿De qué hablamos cuando hablamos de deberes jurídicos? (Algunas consideraciones sobre las fuentes del Derecho a partir de la tesis de Nino del caso especial). Doxa, n. 25, 2002.

RODRIGUES, Leandro Nascimento; LEAL, Pastora do Socorro Teixeira. A eficácia dos direitos fundamentais nas relações privadas à luz da jurisprudência do STF: análise crítica do RE 201. 819-8 e ADI 4815. Revista de Direitos e Garantias Fundamentais, v. 19, n.2 (2018). pp. 11-42.

RUBIO LLORENTE, F. Los deberes constitucionales. Revista Española de Derecho Constitucional, Madrid, v. 21, n. 61, 2001.

RUGGIE, John Gerard. The Social Construction of the UN Guiding Principles on Business and Human Rights. Corporate Responsibility Initiative Working Paper No. 67. Cambridge, MA: John F. Kennedy School of Government, Harvard University. Jun. 2017. 
RUGGIE, John Gerard. Promotion and Protection of All Human Rights, Civil, Political, Economic, Social and Cultural Rights, Including the Right to Development Protect, Respect and Remedy: a Framework for Business and Human Rights. April 7 th, 2008. Disponível em: https://www.businesshumanrights.org/sites/default/ files/reports-and-materials/Ruggie-report-7-Apr-2008.pdf. Acesso em: 11 abr. 2018.

SAGAFI-NEJAD, Tagi. The UN and Transnational Corporations: From Code of Conduct to Global Compact. Bloomington and Indianapolis: Indiana University Press, 2008.

SCHERER, Andreas Georg; PALAZZO, Guido. Globalization and Corporate Social Responsibility. In: CRANE, A.; MCWILLIAMS, A.; MATTEN, D.; MOON, J.; SIEGEL, D.J. (eds). The Oxford Handbook of Corporate Social Responsibility, Oxford: Oxford University Press, 2008. pp. 413-431.

SILVA, Elaini Cristina Gonzaga. A Expansão do Direito Internacional: Uma Questão de Valores. Tese (Doutorado) Faculdade de Direito da Universidade de São Paulo, 2011.w

SIQUEIRA, Julio Pinheiro Faro Homem de. Políticas públicas, deveres fundamentais e concretização de direitos. Revista Brasileira de Políticas Públicas, v. 3, n. 2, 2013. pp. 250-269.

TAVARES, Henrique da Cunha; PEDRA, Adriano Sant'Ana. Accessory Tax Obligations from the Perspective of the Fundamental Duties Theory. Congresso IVR. Belo Horizonte, 2013 (disponibilizado pelos autores).

TOFFLER, Alvin. A terceira onda (7. ed. ed.). Rio de Janeiro: Editora Record, 1980.

UNITED NATIONS. Agenda 21. 1992a.

UNITED NATIONS. The Rio Declaration on Environment and Development. 1992b.

UNEP - Basel Convention. Milestones. 2019. Available at: http://basel.int/TheConvention/ Overview/Milestones/tabid/2270/Default.aspx. Accessed on September 29, 2019.
United Nations - UN. Human Rights and the 2030 Agenda for Sustainable Development. 2016. Available at: . Accessed on 1 August 2016.

UNITED NATIONS - UN. Report of the World Commission on Environment and Development, Our Common Future (UN Doc. A/42/427, 4 August 1987), Annex. Available at: https://sustainabledevelopment. un.org/content/documents/5987ourcommon-future. pdf. Accessed on September 23, 2018.

United Nations: Economic and Social Council. Review of Further Developments in Fields with which the SubComission Has Been Concerned - Human Rights and the Environment: Final report prepared by Mrs. Fatma Zohra Ksentini, Special Rapporteur. 6 July 1994. Available at: https://digitallibrary.un.org/record/226681. Accessed on February 28, 2020.

United Nations Environmental Program - UNEP. Basel Convention on the Control of Transboundary Movements of Hazardous Wastes and their Disposal. 1989. Available at: https://www.basel.int/Portals/4/ Basel\%20Convention/docs/text/BaselConventionText-e.pdf Accessed on September 28, 2019.

UNITED NATIONS GLOBAL COMPACT. The power of principles: Sustainability begins with aprinciples-based approach to doing business. Disponível em: https://www.unglobalcompact.org/what-is-gc/mission/principles. Acesso em: 11 abr. 2018.

United Nations Human Rights Special Procedures. Framework Principles on Human Rights and the Environment: the main human rights obligations relating to the enjoyment of a safe, clean, healthy and sustainable environment. 2018. Available at: https://www. ohchr.org/Documents/Issues/Environment/SREnvironment/FrameworkPrinciplesUserFriendlyVersion. pdf. Accessed on February 27, 2020

VARELA DÍAZ, S. La idea de deber constitucional. Revista Española de Derecho Constitucional, n. 4, 1982.

VERNENGO, R. J. Deberes prescriptivos y deberes descriptivos. Anuario de Filosofia del Derecho. Madrid, p. 263-273, 1993. 
Para publicar na Revista de Direito Internacional, acesse o endereço eletrônico www.rdi.uniceub.br ou www.brazilianjournal.org.

Observe as normas de publicação, para facilitar e agilizar o trabalho de edição. 